\title{
Recruitment of Scc2/4 to double strand breaks depends on yH2A and DNA end resection
}

Martin Scherzer ${ }^{\mathrm{a}}$, Fosco Giordano ${ }^{\mathrm{a}}$, Maria Solé Ferran ${ }^{\mathrm{a}, \mathrm{b}}$ and Lena Ström ${ }^{\mathrm{a}, \mathrm{c}}$

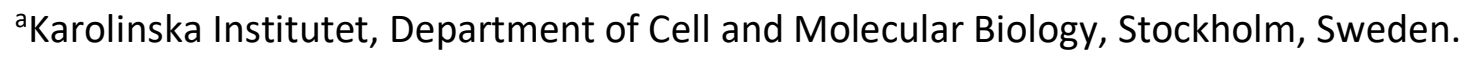

bpresent address: Spanish National Cancer Research centre (CNIO), Melcher Fernandéz Almagro 3, 28029 Madrid, Spain

${ }^{c}$ correspondence: lena.strom@ki.se

Short title: Recruitment of Scc2/4 to DSB

Highlights:

Key words: Scc2/Scc4, Cohesin, DSB, resection

\begin{abstract}
Homologous recombination (HR) enables cells to overcome the threat of DNA double strand breaks (DSB), allowing for repair without the loss of genetic information. Central to the HR repair process is the de novo loading of Cohesin around a DSB by its loader complex Scc2/4. Although Cohesin's accumulation at these sites has been well studied, the prerequisites leading to Scc2/4 recruitment during the repair process are still elusive. Here we investigate which factors are required for recruitment of Scc2 around DSBs in Saccharomyces cerevisiae. To address this question, we combined ChIP-qPCR with a GAL-inducible HO-endonuclease system to generate a site specific DSB in vivo. We find that Scc2 recruitment relies on $\mathrm{yH} 2 \mathrm{~A}$ and Tel1, but as opposed to Cohesin, not on Mec1. We further demonstrate that binding of Scc2 depends on and coincides with DNA end resection. Although affected by the impact on resection, this recruitment of Scc2 is not directly facilitated by the RSC, SWR1 or INO80 complexes. Our results shed light on the intricate DSB repair cascade leading to the recruitment of $\operatorname{Scc} 2 / 4$ and the subsequent loading of Cohesin.
\end{abstract}




\section{Introduction}

A cornerstone in the maintenance of genomic integrity relies on a cells ability to repair DNA damage. This encompasses an orchestrated response necessary to keep its genetic material intact. DNA double strand breaks (DSBs) pose the most hazardous threat to genomic integrity, rendering repair of the same of vital importance[1]. The repair of DSBs is mediated by two major pathways, comprising non-homologous end joining (NHEJ) and homologous recombination (HR). Whereas NHEJ offers rapid repair based on direct end joining, it correlates with increased risk for erroneous repair. HR on the other hand depends on a suitable repair template and is primarily restricted to the S/G2- phases of the cell cycle[2, 3].

The HR repair pathway relies on proteins of the highly conserved Rad52 epistasis group[4]. Among them are Mre11, Rad50 and Xrs2, the constituents of the MRX complex. Credited with the recognition of DSBs, MRX is recruited to broken DNA ends, initiating early stages of DNA end resection and providing a binding platform for the effector kinase Tel1. Recruitment of Tel1 facilitates checkpoint activation, phosphorylation of histone $\mathrm{H} 2 \mathrm{~A}$ and prevents further progression through the cell cycle[5]. The absence of NHEJ-directing Ku proteins in postreplicative cells then allows the initiation of long-range DNA end resection, carried out by the exonucleases Dna2 and Exo1[6]. The resulting 3' overhang ssDNA ends are rapidly bound by RPA and provide a binding substrate for Mec1, which in turn reinforces checkpoint activation[7]. The following replacement of RPA with Rad51 enables search for a repair template and the subsequent synthesis of the lost sequence[8]. The presence of a sister chromatid in S/G2 provides cells with a bona fide template to amend DSBs, with minimized loss of genetic information.

Central to the organization of sister chromatids is the ring-shaped protein complex Cohesin. The core Cohesin complex consists of the Smc1/Smc3 heterodimer ATPase, as well the Kleisin subunit Scc1 and the heat repeat protein Scc3. Capable of entrapping DNA within its ring, Cohesin is loaded onto DNA in early S-phase by the separate loader complex composed of the proteins Scc2 and Scc4 (Scc2/4). Upon acetylation of the Smc3 subunit by Eco1, Cohesin is admitted to tether sister chromatids together, a process referred to as establishment of cohesion[9]. Once loaded, ATP hydrolysis allows Cohesin to relocate from the sites of loading and Scc2/4 itself[10]. This was demonstrated by calibrated ChIP-Seq, where only a weak correlation between Cohesin and Scc2/4 binding was found, unless Cohesin's ATPase function 
was impaired[11]. In anaphase, after formation of the mitotic spindle, the Scc1 subunit is cleaved by Separase, allowing the segregation of sister chromatids[12]. As opposed to yeast, where Cohesin keeps the chromosomes cohesive along their entire lengths until anaphase, higher eukaryotes remove the majority of chromosome arm bound Cohesin by Separaseindependent means already in prophase, leaving only centrometric Cohesin subjected to cleavage of Scc1[13].

The Cohesin complex was first recognized for its significance in DNA DSB repair[14]. It was later shown, that cells were unable to repair DNA damage if they failed to establish cohesion during S-phase[15]. Subsequent experiments demonstrated, that postreplicative de novo loading of Cohesin occurs around the break, spanning a region of about 50kb[16, 17]. In line with its loading in early S-phase for sister chromatid cohesion, this process relies on Scc2/4. It was also shown that NIPBL and Mau2, the human homologues of Scc2 and Scc4 respectively, localize to laser microirradiation induced DNA damage stripes as well as Fok1 generated $\operatorname{DSBs}[18,19]$, however DNA binding at breaks has only formally been demonstrated for Scc2 in yeast[20]. Mounting evidence[21-23] attributes the Cohesin loader with a central role in the DNA damage response, yet prerequisites for its recruitment to DSBs are still elusive, despite numerous factors influencing accumulation of Cohesin at DSBs having been identified[16, 17].

Here we address the requirements for Scc2 recruitment to DNA DSBs in yeast using chromatin immunoprecipitation to assess its binding, in selected genetic mutants. We find that the recruitment is largely driven by Tel1 and phosphorylation of histone H2A, whereas Mec1, contrary to its significance for Cohesin loading, is dispensable for this process. We show that Scc2 binding coincides with DNA end resection, where delayed or accelerated end resection affects Scc2 recruitment in a corresponding manner. We further demonstrate that the RSC, SWR1 and INO80 chromatin remodeling complexes are not directly responsible for its recruitment, but do however affect it, presumably through their impact on end resection. We conclude that DNA end resection, together with $\mathrm{yH} 2 \mathrm{~A}$, is a driving factor for $\mathrm{Scc} 2 / 4$ recruitment to DSBs, yet by itself insufficient to facilitate Cohesin loading. These findings provide insight into the sequence of events essential for Scc2 recruitment and Cohesin loading during the DSB repair and suggest a potential Cohesin-independent role for Scc2/4 at DSBs. 


\section{Materials and methods}

\section{Yeast strains and growth conditions}

All S. cerevisiae strains were of W303 origin (ade2-1 trp1-1 can1-100 leu2-3 his3-11,15 ura3-1 RAD5, GAL, psi+). Yeast extract peptone (YEP) supplemented with $40 \mu \mathrm{g} / \mathrm{ml}$ adenine was used as yeast media, unless otherwise stated. For chromatin immunoprecipitation experiments, cells were grown in YEP media supplemented $2 \%$ raffinose at $25^{\circ} \mathrm{C}$. Arrest in $\mathrm{G} 2 / \mathrm{M}$ was induced by addition of benomyl (381586, Sigma) dissolved in DMSO at a final concentration 8 $\mu \mathrm{g} / \mathrm{ml}$ for 3 hours, and break induction achieved by the addition of $2 \%$ galactose (final) during indicated time periods. Control samples received water. Where applicable, 3-Indoleacetic acid (Auxin - 13750, Sigma) was dissolved in 100\% EtOH and added at a final concentration of $1 \mathrm{mM}$. Doxycycline (D9891, Sigma) was dissolved in 50\% EtOH and added at a final concentration of $5 \mu \mathrm{g} / \mathrm{ml}$. Control samples received the respective amount of EtOH. To create null mutants, the gene of interest was replaced with an antibiotic resistance marker through lithium acetate based transformation. Some strains were crossed to obtain desired genotypes. For a complete list of strains see table S1.

\section{FACS analysis of DNA content}

G2/M arrest was confirmed by flowcytometric analysis. In brief, $1 \mathrm{ml}$ of cultures were fixed overnight in $70 \%$ EtOH. Samples were resuspended in $50 \mathrm{mM}$ Tris- $\mathrm{HCl} \mathrm{pH} 7.8$ and treated with $1 \mathrm{mg} / \mathrm{mL}$ of RNAse A (12091021, ThermoFisher) at $37^{\circ} \mathrm{C}$ overnight. Cells were resuspended in FACS buffer (200mM Tris pH7.5, 211mM NaCl, $78 \mathrm{mM} \mathrm{MgCl}_{2}$ ) containing $5 \mu \mathrm{g} / \mathrm{ml}$ propidium iodide (P4170, Sigma) and sonicated using a Bioruptor Standard (UCD-200, Diagenode). Samples were analysed on a BD FACSCalibur (BD Biosciences) using the CellQuest Pro software.

\section{Protein extraction and western blotting}

To verify Auxin-mediated degradation of target proteins 4 OD units of cells were collected, washed with water and resuspended in glass bead disruption buffer $(20 \mathrm{mM}$ Tris- $\mathrm{HCl} \mathrm{pH} 8.0$, $10 \mathrm{mM} \mathrm{MgCl} 2,1 \mathrm{mM}$ EDTA, $5 \%$ Glycerol, 0,3M ammonium sulfate) supplemented with $1 \mathrm{mM}$ DTT, cOmplete protease inhibitor (Roche) and 1mM PMSF. 0,8g of acid washed glass beads (G4649, Sigma) were added and samples were vortexed on a VXR Basic Vibrax (Fisher 
Scientific) for lysis. Samples were run on Bolt 4-12\% Bis-Tris Plus gels (NW04120BOX, ThermoFisher) before transfer to nitrocellulose membranes (GE10600002, Sigma). Anti-FLAG (F1804, Sigma), anti-cdc11 Antibody (y-415, Santa Cruz), anti-AID tag (CAC-APC004AM-T, 2B Scientific) and anti-HA tag antibody (ab137838, abcam) were used in conjunction with appropriate secondary antibodies from the IRDyes series (Licor) and detected on an Odyssey imaging system (Licor).

\section{Chromatin immunoprecipitation (ChIP) qPCR}

ChIP was performed as described [24], with some modifications. 40 OD units of cells were crosslinked in $1 \%$ formaldehyde for 30 minutes at room temperature, washed twice in $1 x$ cold TBS, frozen in liquid nitrogen after resuspension in lysis buffer $(50 \mathrm{mM}$ Hepes- $\mathrm{KOH} \mathrm{pH} 7.5$, $140 \mathrm{mM} \mathrm{NaCl}, 1 \mathrm{mM}$ EDTA, $0.1 \%$ Na-Deoxycholate, 1\% Triton X-100, 1x cOmplete protease inhibitor (Roche), 1mM PMSF) and mechanically lysed using a 6870 freezer/mill (SPEX, CertiPrep). WCEs were sonicated using a Bandelin Sonopuls HD 2070.2 mounted with an MS73 probe, for optimally sized DNA fragments (300-700 bp). The protein of interest was purified by over-night incubation with anti-FLAG (Sigma, F1804) or anti-RFA antibody (Agrisera, AS07 214), coupled to dynabeads protein A (Invitrogen). Samples were then washed successively $2 x$ with lysis buffer, $2 x$ with lysis buffer $(360 \mathrm{mM} \mathrm{NaCl}), 2 x$ wash buffer $(10 \mathrm{mM}$ Tris-HCl pH 8, 250mM LiCl, 1mM EDTA, 0.5\% Na-Deoxycholate, 0.5\% NP-40) and once with TEbuffer. After elution of samples from the beads in elution buffer $(50 \mathrm{mM}$ Tris- $\mathrm{HCl}$ pH $8,10 \mathrm{mM}$ EDTA, $1 \% \mathrm{SDS}$ ) at $65^{\circ} \mathrm{C}$ for 15 minutes, crosslinking was reversed for both IP and input samples at $65^{\circ} \mathrm{C}$ overnight. After $1 \mathrm{~h}$ RNAse (VWR) and $2 \mathrm{~h}$ Proteinase $\mathrm{K}$ (Sigma) treatment, DNA was purified using a QIAquick PCR Purification Kit (QIAGEN). Analysis of DNA was performed by qPCR using Fast SYBR Green Master Mix (Applied Biosystems) on a 7500 FAST Real Time PCR System (Life technologies). Where applicable, data was normalized to an average of N1 and N2 within the same sample. For a list of primers see table S2.

\section{Measurement of ssDNA at resected DNA ends}

$10 \mathrm{ml}$ of cells $(O D=0.7)$ were collected and resuspended in $500 \mu$ l of extraction buffer $(100 \mathrm{mM}$ $\mathrm{NaCl}, 50 \mathrm{mM}$ Tris-Hcl pH 8.0, 10mM EDTA, 1\%SDS) supplemented with $2 \mu \mathrm{l}$ ß-mercaptoethanol (M6250, Sigma) and $2.5 \mu \mathrm{l}$ of Zymolase $100 \mathrm{~T}(20 \mathrm{mg} / \mathrm{mL})$. Cells were lysed for 30 minutes at $37^{\circ} \mathrm{C}$ followed by 5 minutes at $65^{\circ} \mathrm{C} .250 \mu \mathrm{KOAC}$ was added followed by incubation on ice for 
20 minutes. The lysate was centrifuged and the supernatant was mixed with $0.2 \mathrm{ml}$ of $5 \mathrm{M}$ $\mathrm{NH}_{4} \mathrm{OAC}$ and $1 \mathrm{ml}$ isopropanol. The resulting pellet was dissolved in $100 \mu \mathrm{l}$ of TE and $200 \mu \mathrm{l}$ isopropanol, washed with $80 \% \mathrm{EtOH}$ and resuspended in $50 \mu \mathrm{l}$ of TE. $10 \mu \mathrm{l}$ of each sample were digested with $10 \mathrm{U}$ of Acil (R0551S, NEB) and 10U Msel (R0525S, NEB) in a total reaction volume of $30 \mu \mathrm{l}$ using CutSmart Buffer (27204S, NEB) supplemented with $1 \mu \mathrm{l}$ of Ambion RNAseA (AM2271). The digestion was performed overnight at $37^{\circ} \mathrm{C}$. Undigested control samples were treated equally with the omission of restriction enzymes. Concentration was measured and adjusted if necessary. 5 serial dilutions of 1:5 were made for each sample and then quantified using Fast SYBR Green Master Mix (Applied Biosystems) on a 7500 FAST Real Time PCR System (Life technologies). For a list of primers see table S2. The difference in average cycles $(\Delta \mathrm{Ct})$ between digested and undigested samples was measured and the amount of ssDNA calculated according to[25].

$$
\% \operatorname{ssDNA}=100 /\left(\left(1+2^{\Delta C t}\right) / 2\right)
$$

\section{Pulsed field gel electrophoresis (PFGE)}

Break induction at the HO cut site was confirmed with pulsed field gel electrophoresis. The procedure was carried out as previously described[16]. Briefly, cells were collected and fixed overnight in $70 \% \mathrm{EtOH}$ at $-20^{\circ} \mathrm{C}$. Samples were resuspended in resuspension buffer ( $1 \mathrm{M}$ Tris base pH7.5, 1.2M Sorbitol, 0.5M EDTA) and lysed in SEMZ buffer (1M Sorbitol, 50mM EDTA, $28 \mathrm{mM} \beta$-Mercaptoethanol and $2 \mathrm{mg} / \mathrm{ml}$ Zymolyase $100 \mathrm{~T}$ (IC320932 VWR)), at $37^{\circ} \mathrm{C}$ for 90 minutes. Plugs were then prepared with SEZ buffer (1M Sorbitol, 50mM EDTA, $1 \mathrm{mg} / \mathrm{ml}$ Zymolyase 100T) and 1\% low-melting temperature agarose (A9414, Sigma). Embedded cells were then lysed in EST buffer (10mM Tris pH8, 100mM EDTA and $1 \%$ Sarcosyl) at $37^{\circ} \mathrm{C}$ for 45 minutes. After successive equibrilation in $0,5 \times \mathrm{TBE}$, plugs were loaded on a $1 \%$ PFGE Agarose (1620137, Bio-Rad) gel prepared in 0,5xTBE. Chromosomes were separated on a Biorad Chef DIII (BioRad) at $6 \mathrm{~V} / \mathrm{cm}$ with a 35,4-83,6 second switch time and $120^{\circ}$ included angle for 24 hours. Gels were subsequently subjected to southern blot using standard techniques. The PCR product of primers "-1kb Chr VI cut Fw" and "-0,3kb Chr VI cut Rv" was served as probe for the break site. A control probe for chromosome $\mathrm{V}$ was generated using primers "Southern Chr $\mathrm{V}$ Ctrl Fw" and "Southern Chr V Ctrl Rv" (Table S2). 


\section{Results}

\section{Spatial distribution of Scc2 in the vicinity of a site specific DSB}

Cohesin's dependence on Scc2/4 as a loading factor has been well established, both in vivo[26] and in vitro[27]. Likewise, it was shown that de novo loading of Cohesin at DSBs in postreplicative cells relies on the presence of $\operatorname{Scc} 2[16,17]$. In agreement with this and fortified by previous Chip-on-chip data in budding yeast, Scc2 can be readily detected at elevated levels around a DSB after 90 minutes of break induction [20], although the requirements for its recruitment are still poorly investigated. We have previously shown that NIPBL, the human homolog of Scc2, localizes to Fok1 generated DSBs through interaction with HP1[18]. However, the absence of an HP1 homolog in Saccharomyces cerevisiae[28] raises the question how this recruitment occurs in yeast. To gain insight into this matter, we combined an inducible HO-endonuclease system with ChIP-qPCR to assess the binding of Scc2 around a DSB. An ectopic HO recognition sequence was introduced on Chromosome VI $(206,1 \mathrm{~kb}$ from the left telomere) in equal distance from the centromere and the right telomere, respectively. To make our data comparable between experiments, we utilized previously published lowbinding sites of Scc2 on Chromosome $V$ for normalization of the qPCR results [29]. We focused on Scc2, since Scc2 and Scc4 display identical binding patterns in vivo in studies analyzing their chromatin association in parallel[10]. The general experimental layout is illustrated in Figure $1 \mathrm{~A}$.

Logarithmically growing cells were arrested in G2, followed by addition of either Galactose (+break) to generate a DSB or not (-break) for comparison of Scc2 binding in unchallenged conditions. 90 minutes after break induction samples were collected for ChIP qPCR. At this time point binding of Scc2 increased significantly up to $10 \mathrm{~kb}$ around the DSB compared to unchallenged conditions (Fig 1B). This accumulation was comparable on both sides and increasing towards the break site. As opposed to the reported binding pattern of Cohesin at DSBs $[16,17]$, we found that the most prominent accumulation of Scc2 occurred within $1 \mathrm{~kb}$ of the DSB. However, since the resolution of ChIP is determined by shearing efficiency ( $300-$ $700 \mathrm{bp}$ ), we opted to investigate the requirements for Scc2 binding from $1 \mathrm{~kb}$ and outwards on the left side of the DSB. The accumulation of Scc2 in a non-mutant strain will henceforth be referred to as wild-type (wt). 


\section{DSB recruitment of Scc2 relies on Tel1 but not Mec1}

DSBs are rapidly recognized by the DNA damage sensing Mre11-Rad50-Xrs2 (MRX) complex[30]. Components of the MRX complex have previously been shown to affect the DSB recruitment of yeast and human Cohesin [17, 31]. To investigate the requirement of MRX for Scc2/4 recruitment, we assessed Scc2's binding in strains lacking either Mre11, Rad50 or Xrs2. Our data demonstrates that binding of Scc2 within 5kb of the DSB was significantly reduced in mre $11 \Delta$ and rad50 $\Delta$ cells, whereas recruitment in $x r s 2 \Delta$ was diminished up to $10 \mathrm{~kb}$ (Fig $2 \mathrm{~A}$ ), rendering the MRX complex an integral part in the recruitment of Scc2. This recruitment did not depend on the nuclease activity of Mre11 as binding was unaffected in deficient backgrounds (Fig S1A).

The initial response to a DSB is accompanied by activation of the DNA damage checkpoint, a process largely regulated by the two kinases Tel1 and Mec1[32]. During checkpoint activation, Tel1 is recruited first, showing a high affinity for broken blunt DNA ends [33], whereas recruitment of Mec1 occurs later[5, 34]. Tel1 was previously reported to be recruited to the DSB by the C-terminus of Xrs2[35]. In agreement with this, deletion of Tel1 led to a considerable reduction in Scc2 recruitment to the break site comparable to the absence of Xrs2 (Fig 2B).

Among the first targets of Tel1 is phosphorylation of histone $\mathrm{H} 2 \mathrm{~A}$ at Ser129, referred to as $\mathrm{\gamma H} 2 \mathrm{~A}$ from here on [36]. $\mathrm{\gamma H} 2 \mathrm{~A}$ has been recognized as an early signal of DNA damage in eukaryotes and is required for the assembly of subsequent effector molecules [37]. In line with previous observations for Cohesin[17], recruitment of Scc2 was indeed impaired (Fig 2C) in strains harboring nonphosphorylateable mutations in both homologs of the H2A gene (hta1-S129A and hta2-S129A)[38].

We next asked, whether absence of Mec1, the second master kinase, augmenting phosphorylation of $\mathrm{H} 2 \mathrm{~A}$, would yield similar results as seen for Tel1 (Fig 2B). To our surprise, deletion of Mec1 had no discernable effect on Scc2 recruitment to the DSB (Fig 2D). These results were quite unexpected, as de novo loading of Cohesin at the DSB was previously shown to rely on the presence of Mec1, more so than Tel1 [17, 39].

To validate this apparent and potentially interesting discrepancy between Scc2 and Cohesin we wanted to confirm the importance of Mec1 for Cohesin recruitment. In agreement with 
published results $[17,34]$, Cohesin failed to be loaded at the DSB in a mec1 $\Delta$ background (Fig 3A). These data highlight different prerequisites for recruitment of $\operatorname{Scc} 2 / 4$ and the subsequent loading of Cohesin.

Since Mec1 recruitment to DSBs relies on RPA-bound single-stranded DNA [7] generated by DNA end resection, this opened for the possibility that Scc2 in itself could be important for the resection process. To test this hypothesis, we generated a strain carrying an auxin-inducible degron (AID[40]) allele of Scc2. Addition of Doxycycline and Auxin after the cells were arrested in $\mathrm{G} 2$ led to a substantial reduction in Scc2 protein levels, which remained low during the course of the experiment (Fig 3B). To confirm the lack of Scc2 functionally, we analyzed the accumulation of Cohesin in the presence and absence of a DSB with and without Scc2. Cohesin's Scc1 subunit could be readily detected on DNA (Fig 3B) and in agreement with our previous results for Scc2 (Fig 1B), this binding was significantly increased in the presence of a DSB up to $10 \mathrm{~kb}$ around the break. Absence of Scc2 on the other hand resulted in a significant reduction in global Cohesin binding, as has previously been reported to be a consequence of inactivating the Scc2 temperature sensitive allele, scc2-4[16, 41]. This was true both for general Cohesin binding in the absence of DNA damage, and de novo loading of Cohesin in the presence of a DSB, when compared to control conditions (Fig 3B). Having the possibility to degrade Scc2 efficiently, we next investigated whether Scc2 influenced the degree of resection at the DSB, using a qPCR-based assay adapted from Zierhut et al. [25]. Resection profiles in the presence of Scc2 were comparable to previous studies, reaching around $90 \%$ of resected DNA after $6 \mathrm{~h}$ of break induction $8 \mathrm{~kb}$ from the DSB[42], whereas resection in a sgs $1 \Delta /$ exo1 $\Delta$ background was severely impaired (data not shown). Conversely, the absence of Scc2 did not affect the rate of DNA end resection (Fig S2A).

\section{DNA end resection is a driving factor of Scc2 recruitment}

Considering the modest effect of Mec1 on Scc2 recruitment and Scc2 being insignificant for resection, we decided to investigate the importance of resection for the recruitment of Scc2 to DSBs. To monitor the recruitment of Scc2 in the context of DNA end resection we followed the accumulation of Scc2 over a $6 \mathrm{~h}$ period after break induction, assessing its binding in 90minute intervals. Ongoing break induction led to a constant increase in Scc2 around the break and elevated levels of Scc2 at -30kb from the break site after 6h (Fig 4A). This increase over time was more prevalent closer to the break. Due to the limitation of the qPCR based approach 
to measure ssDNA, relying on restriction enzyme cut sites and enzyme efficiency, we instead decided to assess DNA end resection by using RPA ChIP as a readout. Our data shows, that RPA binding (Fig 4B) followed a similar pattern as observed for Scc2, suggesting that recruitment of Scc2 coincides with and might depend on DNA end resection, as has been shown for its binding at stalled replication forks [43]. This prompted us to increase the time of break induction, to allow for DNA end resection. Given the speed of end resection of around $4-5 \mathrm{~kb} / \mathrm{h}[44,45]$ and the kinetics of break formation, we decided to analyze the recruitment of Scc2 after 180 minutes from here on, as resection proceeds well beyond 10kb (Fig 3B) in the majority of cells at this time. To assess the impact of DNA end resection on Scc2 recruitment, we analyzed its binding in a strain carrying deletions of Sgs1 and Exo1, noted for a severe resection deficiency beyond a few hundred base pairs. Recruitment of Scc2 to the

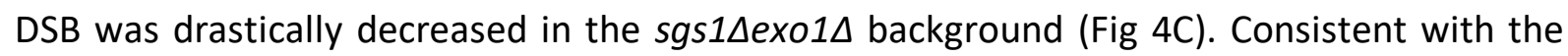
impairment of long-range resection, this effect was less prominent proximal to the break (Fig S2B), confirming the significance of end resection for Scc2 recruitment.

If resection as such is a determining factor for Scc2 recruitment, then increased resection should augment the Scc2 binding. To test this, we assessed Scc2 recruitment in a strain lacking Rad9 which causes DNA end resection to proceed at an accelerated pace[46]. Consistent with our hypothesis, deletion of Rad9 resulted in significantly elevated levels of Scc2 recruitment to the DSB compared to wild type (Fig 3D). Based on our results, we conclude that DNA end resection is a decisive process for Scc2 recruitment, whereas loading of Cohesin requires additional events to take place, such as recruitment of Mec1 (Fig 3A).

A recent study by Arnould et al[47], investigating the role of topologically associating domains (TADs) in DNA damage repair in human cells, proposed a model where a loop extruding mechanism allows rapid phosphorylation of histone $H 2 A X$ as DNA is reeled in by DSB anchored Cohesin. Considering these findings, our observation that Scc2 "emanates" from the break site over time could be explained by Cohesin-mediated loop extrusion. To address the possibility that Scc2/4 would load Cohesin at the break site and then be shuttled away by loop extruding Cohesin, causing a technical artifact, we employed a strain carrying an Scc1-AID construct. This allowed for degradation of Scc1, which consequently would interfere with potential Cohesinmediated loop extrusion at the break. Degradation of Scc1 prior to break induction caused no significant reduction in the recruitment of Scc2 to the DSB (Fig 4E). Interestingly, binding was 
significantly increased $30 \mathrm{~kb}$ from the $\mathrm{DSB}$, raising the possibility that $\mathrm{yH} 2 \mathrm{~A}$ dynamics could also be affected by Cohesin in yeast. A minor, albeit significant, decrease was observed at $5 \mathrm{~kb}$ in unchallenged conditions. Based on these results we conclude that recruitment of Scc2 on one hand occurs independently of Cohesin and that its "emanation" on the other hand is unaffected by possible Cohesin-mediated loop extrusion at DSBs.

\section{Impact of chromatin remodeling on Scc2 recruitment}

Based on our finding that DNA end resection appears to be a critical factor in the recruitment of Scc2, we next addressed the role of chromatin remodeling. As DNA end resection is tightly regulated by chromatin remodeling[48], we channeled our attention first to the RSC complex. It was previously demonstrated that the Sth1 ATPase subunit of the RSC complex acts as a chromatin receptor, facilitating the binding of $\mathrm{Scc} 2 / 4$ and subsequent loading of Cohesin[49]. Given the significance of the RSC complex for loading of Scc2/4 during an unchallenged cell cycle and its central role in the early processing of DSBs[50], we asked whether Sth1 was equally integral for the recruitment of Scc2 to DSBs. Rather surprisingly, recruitment of Scc2 to DSBs at restrictive temperature remained largely comparable to its recruitment at permissive temperature in a strain harboring the temperature sensitive allele sth1-3 (Fig 5A). However, recruitment was overall reduced compared to wild-type (compare to Fig 5C, D), also under permissive conditions.

To corroborate these findings, we in addition utilized a strain expressing AID-tagged Sth1 under a repressible MET3 promoter[49]. Presence of methionine and auxin reduced the Sth1 protein level by more than $80 \%$, prior to break induction (Fig 5B). Unfortunately, cells grown under permissive conditions failed to arrest in $\mathrm{G} 2 / \mathrm{M}$ due to poor growth in minimal media without methionine, combined with Raffinose as a suboptimal carbon source. Despite the absence of the ideal control, recruitment of Scc2 was significantly increased in the presence compared to the absence of a DSB despite Sth1 being absent (Fig 5B), and comparable to the recruitment in the sth1-3 strain (Fig 5A). We thereby conclude that the role of the RSC complex in Scc2/4 loading does not extend to the DNA damage repair response. We reason that the reduction in recruitment is rather due to indirect effects on DNA end resection[50] .

Next, we asked if other chromatin remodelers could be responsible for the recruitment of Scc2 to DSBs. Considering the significance of $\mathrm{yH} 2 \mathrm{~A}$ for the recruitment of Scc2 (Fig 2C), the SWR1- 
C and INO80 chromatin remodeling complexes posed as suitable candidates since both have been shown to be able to bind to yH2A[51, 52]. Deletion of Swr1, the ATPase subunit of SWR1C, lead to a severe reduction in Scc2 at the DSB (Fig 4C). We reason that this might be due to the resulting hampered incorporation of histone $\mathrm{H} 2 \mathrm{AZ}$, negatively affecting DNA end resection[53]. Although described as resection-proficient, RPA coverage in swr1 $\Delta$ confirmed perturbed generation of ssDNA under these experimental conditions (Fig $5 \mathrm{C}$ right graph).

Since the ATPase subunit of INO80 is essential in W303 [54], we decided to address its role for the recruitment of Scc2 by using strains harboring deletions of the Arp8 and the Nhp10 subunits, which interfere with the chromatin remodeling ability and the recruitment of INO80 to DSBs respectively[55]. Interestingly, although both mutants are renowned for deficient DNA end resection[56], only deletion of Nhp10 resulted in a significant reduction in the recruitment of Scc2 to the DSB, whereas deletion of Arp8 remained indistinguishable from wild type (Fig 5D, left graph). However, in agreement with the observed binding pattern for Scc2, only $n h p 10 \Delta$ resulted in a reduction of RPA filament formation around the break, while arp $8 \Delta$ remained comparable to wild type. This discrepancy has been addressed previously, suggesting that DNA end resection is mildly impeded in arp8 8 strains, despite RPA binding remaining unchanged or even slightly increased[57]. Considering RPAs strong affinity for ssDNA[58], we reason that although DNA end resection may be impaired in arp8 $\Delta$, singlestranded nucleofilaments or regions displaying ssDNA may still be able to form, mimicking DNA end resection.

Overall, our data suggest that recruitment of Scc2/4 to DNA DSBs is mediated through phosphorylation of H2A by Tel1, but as contrary to Cohesin not Mec1, and occurs during DNA end resection. We reason that this recruitment is favored by the generation of SSDNA, which occurs during DNA end resection. Furthermore, Scc2/4 recruitment is not directly facilitated by the chromatin remodeling complexes RSC, INO80 or SWR1 as the effect on recruitment was comparable to the degree of impaired resection.

\section{Discussion}

Cohesin's accumulation at DNA DSBs and its dependency on Scc2/4 in any context are both well documented. However, research in the field of DNA damage repair has been focusing 
almost exclusively on Cohesin[59]. In order to get mechanistic insight into how Cohesin is loaded at DSBs it is therefore indispensable to understand how its loader gets there in the first place. Here we provide the first investigation focusing on the recruitment of Scc2 to DNA DSBs in budding yeast. We find that its accumulation depends mainly on $\mathrm{\gamma H} 2 \mathrm{~A}$ and DNA end resection, neither of which alone suffices to facilitate the recruitment. Although Cohesin and its loader share several factors needed for their accumulation at DSBs, our study also uncovered an unexpected difference between the recruitment of Scc2 and the loading of Cohesin. Whereas both Tel1 and Mec1 are required for de novo loading of Cohesin at DSBs, Mec1 is dispensable for the recruitment of Scc2.

The significance of DNA end resection for HR repair is well established, yet only recently its impact on Cohesin is starting to gain traction[43, 60]. We show that Scc2 recruitment emanates from DSBs coincident with ongoing resection. Similar observations have been made for chromatin remodelers modulating DNA end resection[42], however we did not find evidence for Scc2s involvement in this process (Fig S2A). Supported by the fact that Scc2s binding at DSBs was drastically reduced in a sgs $1 \Delta$ /exo1 $1 \Delta$ mutant, this points towards an epistatic relationship of Scc2 recruitment and DNA end resection.

In accord with previous data for Cohesin, we find that the MRX complex is required to facilitate the recruitment of Scc2 to DSBs. This dependency most likely relies on MRX' ability to recruit Tel1 and the resection machinery[61], as recruitment of Scc2 was comparable to wild type in a nuclease-deficient Mre11 D56A \& H125A mutants which still allow complex formation[62, 63] (Fig S1A). It was shown that "clean" DSBs, that is breaks without DNA abducts, can bypass the need for the initial incision at DNA ends by MRX and Sae2 to promote Dna2 and Exo1[64], which would also explain, why deletion of Sae2 had no effect on the accumulation of Scc2 at DSBs (Fig S1B).

Most strikingly, we find that deletion of Mec1, has no effect on Scc2 recruitment, yet impairs Cohesin loading at the DSB. The exact nature of Cohesin's dependency on Mec1 is still unknown. It was shown that phosphorylation of Scc1 at Ser83 by Chk1, presumably downstream of Mec1, was required for the generation of damage induced cohesion, yet loading around the break was unaffected in S83A mutants[39]. Although both Scc2 and Scc4 harbor multiple consensus motifs for Mec1/Tel1[65], we were unable to detect phosphorylation of these sites in response to DNA damage by mass spectrometry (data not 
shown), dampening the possibility of a direct effect on Scc2/4 by either. In vitro experiments have demonstrated that second strand capture of Cohesin is favored if the target is singlestranded. These events were counteracted by addition of RPA[66]. Applying this concept on a DSB, it can be envisioned that Mec1 phosphorylates RPA[67], destabilizing its association with DNA[68] and thereby enabling the loading of Cohesin by Scc2/4. It could also be that recruitment of Mec1 affects the chromatin landscape around the break, as has been observed for stalled replication forks[69], which in turn favors the loading of Cohesin[49].

The requirement of $\mathrm{\gamma H} 2 \mathrm{~A}$ for the recruitment of $\mathrm{Scc} 2$ is consistent with what has been observed for Cohesin[17]. However, previous studies have shown that the hta1-S129A background causes accelerated end resection[70], indicating that DNA end resection by itself is insufficient for Scc2 recruitment. Conversely, it was also shown that $\mathrm{pH} 2 \mathrm{~A}$ spreading increases in the absence of Sgs1/Exo1[71], indicating that also $\mathrm{YH} 2 \mathrm{~A}$ alone is insufficient for Scc2 recruitment. The fact that recruitment of Scc2 was drastically increased in a rad9D background, likewise shown to have accelerated resection kinetics but an unaltered $\mathrm{\gamma H} 2 \mathrm{~A}$ profile[5], lead us to the conclusion that recruitment is not directly mediated by DNA end resection but rather augmented by it.

Due to the complex interplay of DNA end resection and chromatin remodeling, we reasoned that chromatin remodelers could dictate the recruitment of Scc2 depending on the biological context as previous studies have demonstrated to be case for Scc2[49]. Given the role of the RSC complex in the DNA damage response[50] and the requirement of RSC components for Cohesin loading at DSBs[72] we expected similar results for Scc2. Although recruitment was reduced overall compared to genuine wild type cells, we failed to see an effect drastic enough to allow the conclusion that Sth1 serves as an Scc2/4 loading factor at DSBs. We reason that this reduction is rather due to impaired resection kinetics.

Based on our results that Scc2 recruitment depends on $\mathrm{yH} 2 \mathrm{~A}$, we then decided to focus on SWR1C and INO80C, both of which have been proposed to depend on $\mathrm{YH} 2 \mathrm{~A}[52,73]$, though this claim has been contested[71] . Responsible for the H2AZ metabolism at DSBs, SWR1 is recruited to breaks facilitating the incorporation of H2AZ[74], whereas INO80C catalyzes its removal in addition to general nucleosomal eviction[57]. Although in vitro experiments have demonstrated that incorporation of H2AZ benefits DNA end resection, the absence of Swr1 does not cause a resection defect in vivo[42,53]. Seemingly in contrast to our hypothesis, 
recruitment of Scc2 was markedly reduced in swr1 $1 \Delta$. Furthermore, although INO80C mutants have been noted for resection defects, we did not observe a reduction of Scc2 recruitment in $\operatorname{arp} 8 \Delta$ mutants. To circumvent the substantial amount of conflicting data regarding resection defects in these mutants $[57,73,75]$, we decided to measure the generation of ssDNA under our experimental conditions in respective strains. RPA binding agreed with our hypothesis and demonstrated that the RPA filament formation was impaired in swr1 1 and $n h p 10 \Delta$, but increased in arp8 8 , which could account for the slight, albeit insignificant, increase in Scc2 at the DSB. We hypothesize that the reduction of RPA seen in swr $1 \Delta$ cells could be due to delayed HO kinetics[76], although break induction at the experimental endpoint was comparable to wild type (Fig S3C). In support of this, we failed to induce appreciable DSBs in an $h t z 1 \Delta$ background within 3 hours (Fig S3D). We want to note here, that INO80Cs mechanism may be altered depending on laboratory strain background. While the INO80 ATPase subunit is essential in W303, it is not so in S288C[54]. Furthermore, deletion of INO80C components have been shown to cause polyploidy in a S288C derivate strain, with Arp8 being a notable exception[77]. However, we observed significant polyploidy in our arp84 mutant in a W303 background (S3A), which was absent in other strains. In any case, we reached a similar conclusion as with Sth1 and believe that neither SWR1C nor INO80C are directly responsible for recruitment of Scc2 as its binding correlated well with RPA coverage. However, as our investigation did not comprehensively address all chromatin remodelers, we cannot exclude the possibility that other complexes are responsible for Scc2/4 "loading" at DSBs. This would justify a more thorough investigation, beyond the scope of this study.

The exact mechanism that facilitates the recruitment of Scc2 to DSBs remains to be determined. Although ssDNA was shown to be bound poorly by $\operatorname{Scc} 2 / 4$ in vitro, its affinity for Y-fork DNA was comparable to dsDNA[27]. It can be envisioned, that in the process of end resection a similar intermediate is formed, favoring its recruitment. We have previously demonstrated that inactivation of Scc2 in yeast modulates transcription globally and in response to a DSB, affecting DSB proximal genes in particular[23]. Studies in human cells have shown that transcriptional repression at DSBs is mediated by NIPBL and Cohesin[78], whereas in yeast this process is mediated by end resection[70]. Accumulating evidence highlights the significance of RNA and transcription in the DNA damage response and the modulation of 
resection[79]. Considering our data, it would be interesting to address the impact of transcription at DSBs on Scc2 recruitment and vice versa[80].

In summary, we demonstrate that recruitment of $\mathrm{Scc} 2$ relies on phosphorylation of $\mathrm{H} 2 \mathrm{~A}$ by Tel1 and the subsequent resection of DNA. Based on this we propose that DNA end resection affects the loading of Cohesin at DSBs therefore in two ways. First, the actual resection process to mediate the recruitment of $\operatorname{Scc} 2 / 4$. Second, the subsequent recruitment of Mec1, which enables Scc2/4 to load Cohesin at DSB. Together, these data provide a more detailed insight into the events which facilitate the recruitment of Scc2 and subsequent accumulation of Cohesin at DNA DSBs.

\section{Acknowledgements}

We thank Professors C. Björkegren, F. Uhlmann, J. Downs and L. Symington for strains and plasmids. This work was supported by the Swedish Research Council (2016-02206), the Swedish Cancer Society (16 0702), the Bergvall Foundation (2016-01868, 2017-02287), and the KID program at the Karolinska Institutet to L. Ström for M. Scherzer and F. Giordano.

\section{References}

1. Ui A, Chiba N, Yasui A. Relationship among DNA double-strand break (DSB), DSB repair, and transcription prevents genome instability and cancer. Cancer Sci. 2020;111(5):1443-51. Epub 2020/04/02. doi: 10.1111/cas.14404. PubMed PMID: 32232911; PubMed Central PMCID: PMCPMC7226179.

2. Mao Z, Bozzella M, Seluanov A, Gorbunova V. Comparison of nonhomologous end joining and homologous recombination in human cells. DNA Repair (Amst). 2008;7(10):1765-71. Epub 2008/08/05. doi: 10.1016/j.dnarep.2008.06.018. PubMed PMID: 18675941; PubMed Central PMCID: PMCPMC2695993.

3. Zhao X, Wei C, Li J, Xing P, Li J, Zheng S, et al. Cell cycle-dependent control of homologous recombination. Acta Biochim Biophys Sin (Shanghai). 2017;49(8):655-68. Epub 2017/05/26. doi: 10.1093/abbs/gmx055. PubMed PMID: 28541389.

4. Krogh BO, Symington LS. Recombination proteins in yeast. Annu Rev Genet. 2004;38:233-71. Epub 2004/12/01. doi: 10.1146/annurev.genet.38.072902.091500. PubMed PMID: 15568977.

5. Li K, Bronk G, Kondev J, Haber JE. Yeast ATM and ATR kinases use different mechanisms to spread histone $\mathrm{H} 2 \mathrm{~A}$ phosphorylation around a DNA double-strand break. Proc Natl 
Acad Sci U S A. 2020;117(35):21354-63. Epub 2020/08/21. doi: 10.1073/pnas.2002126117. PubMed PMID: 32817543; PubMed Central PMCID: PMCPMC7474660.

6. Symington LS. Mechanism and regulation of DNA end resection in eukaryotes. Crit Rev Biochem Mol Biol. 2016;51(3):195-212. Epub 2016/04/22. doi: 10.3109/10409238.2016.1172552. PubMed PMID: 27098756; PubMed Central PMCID: PMCPMC4957645.

7. Biswas $H$, Goto $G$, Wang W, Sung P, Sugimoto K. Ddc2ATRIP promotes Mec1ATR activation at RPA-ssDNA tracts. PLoS Genet. 2019;15(8):e1008294. Epub 2019/08/02. doi: 10.1371/journal.pgen.1008294. PubMed PMID: 31369547; PubMed Central PMCID: PMCPMC6692047.

8. Krejci L, Altmannova V, Spirek M, Zhao X. Homologous recombination and its regulation. Nucleic Acids Res. 2012;40(13):5795-818. Epub 2012/04/03. doi: 10.1093/nar/gks270. PubMed PMID: 22467216; PubMed Central PMCID: PMCPMC3401455.

9. Uhlmann F, Nasmyth K. Cohesion between sister chromatids must be established during DNA replication. Curr Biol. 1998;8(20):1095-101. Epub 1998/10/21. doi: 10.1016/s09609822(98)70463-4. PubMed PMID: 9778527.

10. Lengronne A, Katou Y, Mori S, Yokobayashi S, Kelly GP, Itoh T, et al. Cohesin relocation from sites of chromosomal loading to places of convergent transcription. Nature.

2004;430(6999):573-8. Epub 2004/07/02. doi: 10.1038/nature02742. PubMed PMID: 15229615; PubMed Central PMCID: PMCPMC2610358.

11. Hu B, Itoh T, Mishra A, Katoh Y, Chan KL, Upcher W, et al. ATP hydrolysis is required for relocating cohesin from sites occupied by its Scc2/4 loading complex. Curr Biol. 2011;21(1):12-24. Epub 2010/12/28. doi: 10.1016/j.cub.2010.12.004. PubMed PMID: 21185190; PubMed Central PMCID: PMCPMC4763544.

12. Uhlmann F, Lottspeich F, Nasmyth K. Sister-chromatid separation at anaphase onset is promoted by cleavage of the cohesin subunit Scc1. Nature. 1999;400(6739):37-42. Epub 1999/07/14. doi: 10.1038/21831. PubMed PMID: 10403247.

13. Waizenegger IC, Hauf S, Meinke A, Peters JM. Two distinct pathways remove mammalian cohesin from chromosome arms in prophase and from centromeres in anaphase. Cell. 2000;103(3):399-410. Epub 2000/11/18. doi: 10.1016/s0092-8674(00)00132-x. PubMed PMID: 11081627.

14. Birkenbihl RP, Subramani S. Cloning and characterization of rad21 an essential gene of Schizosaccharomyces pombe involved in DNA double-strand-break repair. Nucleic Acids Res. 1992;20(24):6605-11. Epub 1992/12/25. doi: 10.1093/nar/20.24.6605. PubMed PMID: 1480481; PubMed Central PMCID: PMCPMC334577.

15. Sjogren C, Nasmyth K. Sister chromatid cohesion is required for postreplicative doublestrand break repair in Saccharomyces cerevisiae. Curr Biol. 2001;11(12):991-5. Epub 2001/07/13. doi: 10.1016/s0960-9822(01)00271-8. PubMed PMID: 11448778.

16. Strom L, Lindroos HB, Shirahige K, Sjogren C. Postreplicative recruitment of cohesin to double-strand breaks is required for DNA repair. Mol Cell. 2004;16(6):1003-15. Epub 2004/12/22. doi: 10.1016/j.molcel.2004.11.026. PubMed PMID: 15610742.

17. Unal E, Arbel-Eden A, Sattler U, Shroff R, Lichten M, Haber JE, et al. DNA damage response pathway uses histone modification to assemble a double-strand break-specific cohesin domain. Mol Cell. 2004;16(6):991-1002. Epub 2004/12/22. doi: 10.1016/j.molcel.2004.11.027. PubMed PMID: 15610741.

18. Bot C, Pfeiffer A, Giordano F, Manjeera DE, Dantuma NP, Strom L. Independent mechanisms recruit the cohesin loader protein NIPBL to sites of DNA damage. J Cell Sci. 2017;130(6):1134-46. Epub 2017/02/09. doi: 10.1242/jcs.197236. PubMed PMID: 28167679; PubMed Central PMCID: PMCPMC5358341.

19. Oka Y, Suzuki K, Yamauchi M, Mitsutake N, Yamashita S. Recruitment of the cohesin loading factor NIPBL to DNA double-strand breaks depends on MDC1, RNF168 and HP1gamma in human cells. Biochem Biophys Res Commun. 2011;411(4):762-7. Epub 2011/07/26. doi: 10.1016/j.bbrc.2011.07.021. PubMed PMID: 21784059. 
20.

Strom L, Karlsson C, Lindroos HB, Wedahl S, Katou Y, Shirahige K, et al. Postreplicative formation of cohesion is required for repair and induced by a single DNA break. Science.

2007;317(5835):242-5. Epub 2007/07/14. doi: 10.1126/science.1140649. PubMed PMID: 17626884. 21. Olley G, Pradeepa MM, Grimes GR, Piquet S, Polo SE, FitzPatrick DR, et al. Cornelia de Lange syndrome-associated mutations cause a DNA damage signalling and repair defect. Nat Commun. 2021;12(1):3127. Epub 2021/05/27. doi: 10.1038/s41467-021-23500-6. PubMed PMID: 34035299; PubMed Central PMCID: PMCPMC8149872.

22. Lightfoot J, Testori S, Barroso C, Martinez-Perez E. Loading of meiotic cohesin by SCC-2 is required for early processing of DSBs and for the DNA damage checkpoint. Curr Biol. 2011;21(17):1421-30. Epub 2011/08/23. doi: 10.1016/j.cub.2011.07.007. PubMed PMID: 21856158. 23. Lindgren E, Hagg S, Giordano F, Bjorkegren J, Strom L. Inactivation of the budding yeast cohesin loader Scc2 alters gene expression both globally and in response to a single DNA double strand break. Cell Cycle. 2014;13(23):3645-58. Epub 2014/12/09. doi: 10.4161/15384101.2014.964108. PubMed PMID: 25483075; PubMed Central PMCID: PMCPMC4612677.

24. Enervald E, Lindgren E, Katou Y, Shirahige K, Strom L. Importance of Poleta for damage-induced cohesion reveals differential regulation of cohesion establishment at the break site and genome-wide. PLoS Genet. 2013;9(1):e1003158. Epub 2013/01/18. doi:

10.1371/journal.pgen.1003158. PubMed PMID: 23326240; PubMed Central PMCID: PMCPMC3542068.

25. Zierhut C, Diffley JF. Break dosage, cell cycle stage and DNA replication influence DNA double strand break response. EMBO J. 2008;27(13):1875-85. Epub 2008/05/31. doi: 10.1038/emboj.2008.111. PubMed PMID: 18511906; PubMed Central PMCID: PMCPMC2413190. 26. Ocampo-Hafalla MT, Uhlmann F. Cohesin loading and sliding. J Cell Sci. 2011;124(Pt 5):685-91. Epub 2011/02/16. doi: 10.1242/jcs.073866. PubMed PMID: 21321326.

27. Murayama Y, Uhlmann F. Biochemical reconstitution of topological DNA binding by the cohesin ring. Nature. 2014;505(7483):367-71. Epub 2013/12/03. doi: 10.1038/nature12867. PubMed PMID: 24291789; PubMed Central PMCID: PMCPMC3907785.

28. Lomberk G, Wallrath L, Urrutia R. The Heterochromatin Protein 1 family. Genome Biol. 2006;7(7):228. Epub 2007/01/17. doi: 10.1186/gb-2006-7-7-228. PubMed PMID: 17224041; PubMed Central PMCID: PMCPMC1779566.

29. Lopez-Serra L, Kelly G, Patel H, Stewart A, Uhlmann F. The Scc2-Scc4 complex acts in sister chromatid cohesion and transcriptional regulation by maintaining nucleosome-free regions. Nat Genet. 2014;46(10):1147-51. Epub 2014/09/01. doi: 10.1038/ng.3080. PubMed PMID: 25173104; PubMed Central PMCID: PMCPMC4177232.

30. Casari E, Rinaldi C, Marsella A, Gnugnoli M, Colombo CV, Bonetti D, et al. Processing of DNA Double-Strand Breaks by the MRX Complex in a Chromatin Context. Front Mol Biosci. 2019;6:43. Epub 2019/06/25. doi: 10.3389/fmolb.2019.00043. PubMed PMID: 31231660; PubMed Central PMCID: PMCPMC6567933.

31. Kim JS, Krasieva TB, LaMorte V, Taylor AM, Yokomori K. Specific recruitment of human cohesin to laser-induced DNA damage. J Biol Chem. 2002;277(47):45149-53. Epub 2002/09/14. doi: 10.1074/jbc.M209123200. PubMed PMID: 12228239.

32. Gobbini E, Cesena D, Galbiati A, Lockhart A, Longhese MP. Interplays between ATM/Tel1 and ATR/Mec1 in sensing and signaling DNA double-strand breaks. DNA Repair (Amst). 2013;12(10):791-9. Epub 2013/08/21. doi: 10.1016/j.dnarep.2013.07.009. PubMed PMID: 23953933. 33. Gobbini E, Cassani C, Villa M, Bonetti D, Longhese MP. Functions and regulation of the MRX complex at DNA double-strand breaks. Microb Cell. 2016;3(8):329-37. Epub 2017/03/31. doi: 10.15698/mic2016.08.517. PubMed PMID: 28357369; PubMed Central PMCID: PMCPMC5349012. 34. Zou L, Elledge SJ. Sensing DNA damage through ATRIP recognition of RPA-sSDNA complexes. Science. 2003;300(5625):1542-8. Epub 2003/06/07. doi: 10.1126/science.1083430. PubMed PMID: 12791985. 
35.

Nakada D, Matsumoto K, Sugimoto K. ATM-related Tel1 associates with double-strand breaks through an Xrs2-dependent mechanism. Genes Dev. 2003;17(16):1957-62. Epub 2003/08/19. doi: 10.1101/gad.1099003. PubMed PMID: 12923051; PubMed Central PMCID: PMCPMC196250. 36. Shroff R, Arbel-Eden A, Pilch D, Ira G, Bonner WM, Petrini JH, et al. Distribution and dynamics of chromatin modification induced by a defined DNA double-strand break. Curr Biol. 2004;14(19):1703-11. Epub 2004/10/02. doi: 10.1016/j.cub.2004.09.047. PubMed PMID: 15458641; PubMed Central PMCID: PMCPMC4493763.

37. Podhorecka M, Skladanowski A, Bozko P. H2AX Phosphorylation: Its Role in DNA Damage Response and Cancer Therapy. J Nucleic Acids. 2010;2010. Epub 2010/09/03. doi: 10.4061/2010/920161. PubMed PMID: 20811597; PubMed Central PMCID: PMCPMC2929501. 38. Downs JA, Lowndes NF, Jackson SP. A role for Saccharomyces cerevisiae histone H2A in DNA repair. Nature. 2000;408(6815):1001-4. Epub 2001/01/05. doi: 10.1038/35050000. PubMed PMID: 11140636.

39. Heidinger-Pauli JM, Unal E, Guacci V, Koshland D. The kleisin subunit of cohesin dictates damage-induced cohesion. Mol Cell. 2008;31(1):47-56. Epub 2008/07/11. doi: 10.1016/j.molcel.2008.06.005. PubMed PMID: 18614046.

40. Nishimura K, Fukagawa T, Takisawa H, Kakimoto T, Kanemaki M. An auxin-based degron system for the rapid depletion of proteins in nonplant cells. Nat Methods. 2009;6(12):917-22. Epub 2009/11/17. doi: 10.1038/nmeth.1401. PubMed PMID: 19915560.

41. Ciosk R, Shirayama M, Shevchenko A, Tanaka T, Toth A, Shevchenko A, et al. Cohesin's binding to chromosomes depends on a separate complex consisting of Scc2 and Scc4 proteins. Mol Cell. 2000;5(2):243-54. Epub 2000/07/06. doi: 10.1016/s1097-2765(00)80420-7. PubMed PMID: 10882066 .

42. Chen X, Cui D, Papusha A, Zhang X, Chu CD, Tang J, et al. The Fun30 nucleosome remodeller promotes resection of DNA double-strand break ends. Nature. 2012;489(7417):576-80. Epub 2012/09/11. doi: 10.1038/nature11355. PubMed PMID: 22960743; PubMed Central PMCID: PMCPMC3640768.

43. Delamarre A, Barthe A, de la Roche Saint-Andre C, Luciano P, Forey R, Padioleau I, et al. MRX Increases Chromatin Accessibility at Stalled Replication Forks to Promote Nascent DNA Resection and Cohesin Loading. Mol Cell. 2020;77(2):395-410 e3. Epub 2019/11/25. doi: 10.1016/j.molcel.2019.10.029. PubMed PMID: 31759824.

44. Zhu Z, Chung WH, Shim EY, Lee SE, Ira G. Sgs1 helicase and two nucleases Dna2 and Exo1 resect DNA double-strand break ends. Cell. 2008;134(6):981-94. Epub 2008/09/23. doi: 10.1016/j.cell.2008.08.037. PubMed PMID: 18805091; PubMed Central PMCID: PMCPMC2662516. 45. Vaze MB, Pellicioli A, Lee SE, Ira G, Liberi G, Arbel-Eden A, et al. Recovery from checkpoint-mediated arrest after repair of a double-strand break requires Srs2 helicase. Mol Cell. 2002;10(2):373-85. Epub 2002/08/23. doi: 10.1016/s1097-2765(02)00593-2. PubMed PMID: 12191482.

46. Bonetti D, Villa M, Gobbini E, Cassani C, Tedeschi G, Longhese MP. Escape of Sgs1 from Rad9 inhibition reduces the requirement for Sae2 and functional MRX in DNA end resection. EMBO Rep. 2015;16(3):351-61. Epub 2015/02/01. doi: 10.15252/embr.201439764. PubMed PMID: 25637499; PubMed Central PMCID: PMCPMC4364874.

47. Arnould C, Rocher V, Finoux AL, Clouaire T, Li K, Zhou F, et al. Loop extrusion as a mechanism for formation of DNA damage repair foci. Nature. 2021;590(7847):660-5. Epub 2021/02/19. doi: 10.1038/s41586-021-03193-z. PubMed PMID: 33597753; PubMed Central PMCID: PMCPMC7116834.

48. Zhao F, Kim W, Kloeber JA, Lou Z. DNA end resection and its role in DNA replication and DSB repair choice in mammalian cells. Exp Mol Med. 2020;52(10):1705-14. Epub 2020/10/31. doi: 10.1038/s12276-020-00519-1. PubMed PMID: 33122806; PubMed Central PMCID: PMCPMC8080561.

49. Munoz S, Minamino M, Casas-Delucchi CS, Patel H, Uhlmann F. A Role for Chromatin Remodeling in Cohesin Loading onto Chromosomes. Mol Cell. 2019;74(4):664-73 e5. Epub 
2019/03/30. doi: 10.1016/j.molcel.2019.02.027. PubMed PMID: 30922844; PubMed Central PMCID: PMCPMC6527865.

50. Shim EY, Hong SJ, Oum JH, Yanez Y, Zhang Y, Lee SE. RSC mobilizes nucleosomes to improve accessibility of repair machinery to the damaged chromatin. Mol Cell Biol. 2007;27(5):160213. Epub 2006/12/21. doi: 10.1128/MCB.01956-06. PubMed PMID: 17178837; PubMed Central PMCID: PMCPMC1820475.

51. Downs JA, Allard S, Jobin-Robitaille O, Javaheri A, Auger A, Bouchard N, et al. Binding of chromatin-modifying activities to phosphorylated histone $\mathrm{H} 2 \mathrm{~A}$ at DNA damage sites. Mol Cell. 2004;16(6):979-90. Epub 2004/12/22. doi: 10.1016/j.molcel.2004.12.003. PubMed PMID: 15610740. 52. Morrison AJ, Highland J, Krogan NJ, Arbel-Eden A, Greenblatt JF, Haber JE, et al. INO80 and gamma-H2AX interaction links ATP-dependent chromatin remodeling to DNA damage repair. Cell. 2004;119(6):767-75. Epub 2004/12/21. doi: 10.1016/j.cell.2004.11.037. PubMed PMID: 15607974.

53. $\quad$ Adkins NL, Niu H, Sung P, Peterson CL. Nucleosome dynamics regulates DNA processing. Nat Struct Mol Biol. 2013;20(7):836-42. Epub 2013/06/04. doi: 10.1038/nsmb.2585. PubMed PMID: 23728291; PubMed Central PMCID: PMCPMC3711194.

54. Au TJ, Rodriguez J, Vincent JA, Tsukiyama T. ATP-dependent chromatin remodeling factors tune S phase checkpoint activity. Mol Cell Biol. 2011;31(22):4454-63. Epub 2011/09/21. doi: 10.1128/MCB.05931-11. PubMed PMID: 21930788; PubMed Central PMCID: PMCPMC3209248. 55. Morrison AJ, Shen X. Chromatin remodelling beyond transcription: the INO80 and SWR1 complexes. Nat Rev Mol Cell Biol. 2009;10(6):373-84. Epub 2009/05/09. doi: 10.1038/nrm2693. PubMed PMID: 19424290; PubMed Central PMCID: PMCPMC6103619. 56. Morrison AJ, Kim JA, Person MD, Highland J, Xiao J, Wehr TS, et al. Mec1/Tel1 phosphorylation of the INO80 chromatin remodeling complex influences DNA damage checkpoint responses. Cell. 2007;130(3):499-511. Epub 2007/08/19. doi: 10.1016/j.cell.2007.06.010. PubMed PMID: 17693258.

57. Lademann CA, Renkawitz J, Pfander B, Jentsch S. The INO80 Complex Removes H2A.Z to Promote Presynaptic Filament Formation during Homologous Recombination. Cell Rep. 2017;19(7):1294-303. Epub 2017/05/18. doi: 10.1016/j.celrep.2017.04.051. PubMed PMID: 28514650.

58. Yates LA, Aramayo RJ, Pokhrel N, Caldwell CC, Kaplan JA, Perera RL, et al. A structural and dynamic model for the assembly of Replication Protein A on single-stranded DNA. Nat Commun. 2018;9(1):5447. Epub 2018/12/24. doi: 10.1038/s41467-018-07883-7. PubMed PMID: 30575763; PubMed Central PMCID: PMCPMC6303327.

59. Litwin I, Pilarczyk E, Wysocki R. The Emerging Role of Cohesin in the DNA Damage Response. Genes (Basel). 2018;9(12). Epub 2018/11/30. doi: 10.3390/genes9120581. PubMed PMID: 30487431; PubMed Central PMCID: PMCPMC6316000.

60. Auréle Piazza HB, Agnès Dumont, Agnès Thierry, Jérome Savocco, Fabien Gerard, Romain Koszul. Cohesin regulates homology search during recombinational DNA repair. bioRxiv. 2020;2020.12.17. doi: https://doi.org/10.1101/2020.12.17.423195.

61. Shim EY, Chung WH, Nicolette ML, Zhang Y, Davis M, Zhu Z, et al. Saccharomyces cerevisiae Mre11/Rad50/Xrs2 and Ku proteins regulate association of Exo1 and Dna2 with DNA breaks. EMBO J. 2010;29(19):3370-80. Epub 2010/09/14. doi: 10.1038/emboj.2010.219. PubMed PMID: 20834227; PubMed Central PMCID: PMCPMC2957216.

62. Lewis LK, Storici F, Van Komen S, Calero S, Sung P, Resnick MA. Role of the nuclease activity of Saccharomyces cerevisiae Mre11 in repair of DNA double-strand breaks in mitotic cells. Genetics. 2004;166(4):1701-13. Epub 2004/05/06. doi: 10.1534/genetics.166.4.1701. PubMed PMID: 15126391; PubMed Central PMCID: PMCPMC1470833.

63. Krogh BO, Llorente B, Lam A, Symington LS. Mutations in Mre11 phosphoesterase motif I that impair Saccharomyces cerevisiae Mre11-Rad50-Xrs2 complex stability in addition to nuclease activity. Genetics. 2005;171(4):1561-70. Epub 2005/09/07. doi: 
10.1534/genetics.105.049478. PubMed PMID: 16143598; PubMed Central PMCID: PMCPMC1456084.

64. Paudyal SC, Li S, Yan H, Hunter T, You Z. Dna2 initiates resection at clean DNA doublestrand breaks. Nucleic Acids Res. 2017;45(20):11766-81. Epub 2017/10/06. doi: 10.1093/nar/gkx830. PubMed PMID: 28981724; PubMed Central PMCID: PMCPMC5714177.

65. Cheung HC, San Lucas FA, Hicks S, Chang K, Bertuch AA, Ribes-Zamora A. An S/T-Q cluster domain census unveils new putative targets under Tel1/Mec1 control. BMC Genomics. 2012;13:664. Epub 2012/11/28. doi: 10.1186/1471-2164-13-664. PubMed PMID: 23176708; PubMed Central PMCID: PMCPMC3564818.

66. Murayama Y, Samora CP, Kurokawa Y, Iwasaki H, Uhlmann F. Establishment of DNADNA Interactions by the Cohesin Ring. Cell. 2018;172(3):465-77 e15. Epub 2018/01/24. doi: 10.1016/j.cell.2017.12.021. PubMed PMID: 29358048; PubMed Central PMCID: PMCPMC5786502. 67. Brush GS, Morrow DM, Hieter P, Kelly TJ. The ATM homologue MEC1 is required for phosphorylation of replication protein A in yeast. Proc Natl Acad Sci U S A. 1996;93(26):15075-80. Epub 1996/12/24. doi: 10.1073/pnas.93.26.15075. PubMed PMID: 8986766; PubMed Central PMCID: PMCPMC26358.

68. Vassin VM, Wold MS, Borowiec JA. Replication protein A (RPA) phosphorylation prevents RPA association with replication centers. Mol Cell Biol. 2004;24(5):1930-43. Epub 2004/02/18. doi: 10.1128/MCB.24.5.1930-1943.2004. PubMed PMID: 14966274; PubMed Central PMCID: PMCPMC350552.

69. Rodriguez J, Tsukiyama T. ATR-like kinase Mec1 facilitates both chromatin accessibility at DNA replication forks and replication fork progression during replication stress. Genes Dev. 2013;27(1):74-86. Epub 2013/01/12. doi: 10.1101/gad.202978.112. PubMed PMID: 23307868; PubMed Central PMCID: PMCPMC3553285.

70. Manfrini N, Clerici M, Wery M, Colombo CV, Descrimes M, Morillon A, et al. Resection is responsible for loss of transcription around a double-strand break in Saccharomyces cerevisiae. Elife. 2015;4. Epub 2015/08/01. doi: 10.7554/eLife.08942. PubMed PMID: 26231041; PubMed Central PMCID: PMCPMC4541074.

71. Bennett G, Papamichos-Chronakis M, Peterson CL. DNA repair choice defines a common pathway for recruitment of chromatin regulators. Nat Commun. 2013;4:2084. Epub 2013/07/03. doi: 10.1038/ncomms3084. PubMed PMID: 23811932; PubMed Central PMCID: PMCPMC3731036.

72. Oum JH, Seong C, Kwon Y, Ji JH, Sid A, Ramakrishnan S, et al. RSC facilitates Rad59dependent homologous recombination between sister chromatids by promoting cohesin loading at DNA double-strand breaks. Mol Cell Biol. 2011;31(19):3924-37. Epub 2011/08/03. doi: 10.1128/MCB.01269-10. PubMed PMID: 21807899; PubMed Central PMCID: PMCPMC3187356. 73. van Attikum H, Fritsch O, Gasser SM. Distinct roles for SWR1 and INO80 chromatin remodeling complexes at chromosomal double-strand breaks. EMBO J. 2007;26(18):4113-25. Epub 2007/09/01. doi: 10.1038/sj.emboj.7601835. PubMed PMID: 17762868; PubMed Central PMCID: PMCPMC2230671.

74. $\quad$ Kalocsay M, Hiller NJ, Jentsch S. Chromosome-wide Rad51 spreading and SUMOH2A.Z-dependent chromosome fixation in response to a persistent DNA double-strand break. Mol Cell. 2009;33(3):335-43. Epub 2009/02/17. doi: 10.1016/j.molcel.2009.01.016. PubMed PMID: 19217407.

75. Tsukuda T, Fleming AB, Nickoloff JA, Osley MA. Chromatin remodelling at a DNA double-strand break site in Saccharomyces cerevisiae. Nature. 2005;438(7066):379-83. Epub 2005/11/18. doi: 10.1038/nature04148. PubMed PMID: 16292314; PubMed Central PMCID: PMCPMC1388271.

76. Morillo-Huesca M, Clemente-Ruiz M, Andujar E, Prado F. The SWR1 histone replacement complex causes genetic instability and genome-wide transcription misregulation in the absence of H2A.Z. PLoS One. 2010;5(8):e12143. Epub 2010/08/17. doi: 
10.1371/journal.pone.0012143. PubMed PMID: 20711347; PubMed Central PMCID: PMCPMC2920830.

77. Chambers AL, Ormerod G, Durley SC, Sing TL, Brown GW, Kent NA, et al. The INO80 chromatin remodeling complex prevents polyploidy and maintains normal chromatin structure at centromeres. Genes Dev. 2012;26(23):2590-603. Epub 2012/12/05. doi: 10.1101/gad.199976.112. PubMed PMID: 23207916; PubMed Central PMCID: PMCPMC3521627.

78. Meisenberg C, Pinder SI, Hopkins SR, Wooller SK, Benstead-Hume G, Pearl FMG, et al. Repression of Transcription at DNA Breaks Requires Cohesin throughout Interphase and Prevents Genome Instability. Mol Cell. 2019;73(2):212-23 e7. Epub 2018/12/18. doi: 10.1016/j.molcel.2018.11.001. PubMed PMID: 30554942; PubMed Central PMCID: PMCPMC6344341.

79. Storici F, Bebenek K, Kunkel TA, Gordenin DA, Resnick MA. RNA-templated DNA repair. Nature. 2007;447(7142):338-41. Epub 2007/04/13. doi: 10.1038/nature05720. PubMed PMID: 17429354; PubMed Central PMCID: PMCPMC2121219.

80. Domingo-Prim J, Endara-Coll M, Bonath F, Jimeno S, Prados-Carvajal R, Friedlander MR, et al. EXOSC10 is required for RPA assembly and controlled DNA end resection at DNA doublestrand breaks. Nat Commun. 2019;10(1):2135. Epub 2019/05/16. doi: 10.1038/s41467-019-10153-9. PubMed PMID: 31086179; PubMed Central PMCID: PMCPMC6513946.

\section{Figure Legends}

\section{Figure 1. Scc2 is recruited DNA DSBs}

a) Schematic of the basic experimental setup. Cells in exponential growth phase were arrested in $\mathrm{G} 2$ by addition of benomyl for 3h. Galactose was added to induce a DNA DSB on the arm of chromosome 6 in equal distance to the centromere and telomere. Where applicable, cells without induction received water for the same amount of time. After break induction samples were collected and binding of the protein of interest was assessed by ChIP qPCR. Primers used are indicated according to their distance, with "-" referring to upstream and "+" referring to downstream, to the break site. Cells were grown at $25^{\circ} \mathrm{C}$ throughout. b) Scc2 binding is significantly elevated up to $10 \mathrm{~kb}$ around a DSB, 90 minutes after break induction (red), compared to no break (blue). Data was normalized to low-binding sites. The graph shows means and SD of $n=3$. Student's t-test was used to compare +break and -break at respective locations. Significance: ${ }^{*} p<0,05 ;{ }^{* *} p<0,01 ;{ }^{* *} p<0,001 ;$ ns $=$ not significant.

Figure 2. Recruitment of Scc2 depends on the MRX complex, yH2A and Tel1 but not Mec1

ChIP-qPCR of Scc2 binding at the DSB in (a-d) wt and strains lacking a) Mre11, Rad50 or Xrs, b) Tel1 c) phosphorylatable alleles of histone H2A or d) Mec1. The graphs show means and SD of $n=3$. Student's t-test was used to compare normalized values of Scc2 between wt and 
indicated mutants at respective locations, 90 minutes after break induction. Significance: ${ }^{*} p$ $<0,05 ; * p<0,01 ; * * p<0,001 ;$ ns = not significant.

\section{Figure 3. Cohesin relies on Mec1 to be loaded at DSBs by Scc2/4}

a) ChIP-qPCR of Scc1 binding at the DSB in a wild type and a mec1 $\Delta$ strain. b) Left: ChIP-qPCR of Scc1 binding at a DSB in the presence or absence of Scc2 in an Scc2 degron strain. Cells were grown and arrested as indicated in Figure 1. Prior to break induction, cultures were split in two, with one half receiving Auxin and Doxycycline and the other half receiving a corresponding amount of EtOH for 2 hours to degrade Scc2 or not. Each culture was then split again, totaling 4 and receiving either galactose or water. Right: Western blot showing protein levels of Scc2. Protein samples were taken after 3 hours arrest (G2/M, lane 1), subsequent 2 hours of either IAA/Doxy (+IAA/Dox, lane 2) or EtOH (-IAA/Dox, lane 5) incubation and following 3 hours of either break induction in the presence (-IAA/Dox +break, lane 7) and absence of Scc2 (+IAA/Dox +break, lane 4) or under no break condition in in the presence (IAA/Dox -break, lane 6) and absence of Scc2 (+IAA/Dox -break, lane 3). Cdc11 served as a loading control. The graphs show means and SD of a) $n=3$ and b) $n=2$. Student's t-test was used to compare values of Scc1 between a) wt and mec1s or b) +break and -break in the presence or absence of Scc2 at respective locations, 180 minutes after break induction. Significance: ${ }^{*} p<0,05 ;{ }^{* *} p<0,01 ;{ }^{* *} p<0,001 ;$ ns = not significant.

\section{Figure 4. Scc2 binding at DSBs accumulates over time and depends on DNA end resection}

ChIP-qPCR time course of a) Scc2 and b) RPA binding at the DSB. Samples were taken over a 6 hour period at 90 minute intervals. A log2 scale was used to visualize RPA binding. ChIP-qPCR of Scc2 binding at a DSB in (c\&d) wt and strains lacking c) Sgs1 \& Exo1 d) Rad9. e) Left: ChIPqPCR of Scc2 binding at a DSB in the presence or absence of Scc1 in an Scc1 degron strain. Cells were grown and arrested as indicated in Figure 1. Prior to break induction, cultures were split in two, with one half receiving Auxin and Doxycycline and the other half receiving an equal and appropiate amount of EtOH for 2 hours to degrade Scc1 or not. Each culture was then split again, totaling 4 and receiving either galactose or water. Right: Western blot showing protein levels of Scc1. Protein samples were taken after 3 hours arrest (G2/M, lane 1), subsequent 2 hours of either IAA/Doxy (+IAA/Dox, lane 2) or EtOH (-IAA/Dox, lane 5) incubation and following 3 hours of either break induction in the presence (-IAA/Dox +break, 
lane 7) and absence of Scc1 (+IAA/Dox +break, lane 4) or under no break condition in in the presence (-IAA/Dox -break, lane 6) and absence of Scc1 (+IAA/Dox -break, lane 3). Cdc11 served as a loading control. Graphs show means and SD of $(\mathbf{a}, \mathbf{b} \& \mathbf{e}) \mathrm{n}=2$ and $(\mathbf{c} \& \mathbf{d}) \mathrm{n}=3$. Student's t-test was used to compare values of Scc2 between wt and c) $\operatorname{sgs} 1 \Delta /$ exo1 $1 \Delta$ or d) rad9 $\Delta$ at respective locations, 180 minutes after break induction. In e) binding of Scc2 in +break was compared between the presence or absence of Scc1 at respective locations, 180 minutes after break induction. Significance: ${ }^{*} p<0,05 ;{ }^{*} p<0,01 ; * * p<0,001$; ns $=$ not significant.

\section{Figure 5. Scc2 recruitment is not directly facilitated by RSC, SWR1 or INO80}

a) ChIP-qPCR of Scc2 binding at the DSB in an sth1-3 background. Cells were grown and arrested as indicated in Figure 1. 30 minutes prior to break induction, cultures were split into two with half grown at $25^{\circ} \mathrm{C}$ and the other half grown at $37^{\circ} \mathrm{C}$ to inactivate Sth1. Each culture was then split again, totaling 4 and receiving either galactose or water. b) Left: ChIP-qPCR of Scc2 binding without Sth1 in the presence of absence of a DSB. Cells were grown in -met media and shifted to benomyl containing YEP media supplemented with $2 \mathrm{mM}$ Methionine for 3 hours. Cultures were then split, totaling 2 and receiving either galactose or water. Poor growth prohibited arrest in -met media, denying analysis of suitable control conditions. Right: Western blot showing protein levels of Sth1. Protein samples were taken after 3 hours arrest $(\mathrm{G} 2 / \mathrm{M}$, lane 1), 3 hours after arrest (+IAA/Met, lane 2) and following break induction (+IAA/Met +break, lane 4) or not (+IAA/Met -break, lane 3). Cdc11 served as a loading control. c) ChIP-qPCR of Scc2 (left) or RPA (right) binding at a DSB in wt and swr1 . d) ChIP-qPCR of Scc2 (left) or RPA (right) binding at a DSB in wt, arp8 and nhp10 . Graphs show means and $\mathrm{SD}$ of $\mathrm{n}=3$. Student's t-test was used to compare normalized values of Scc2 between a) +break with and without Sth1 b) in the absence of Sth1 with and without break c \& d) wt and indicated mutants at respective locations, 180 minutes after break induction. c \& d) Additionally, a student's t-test was used to compare normalized values of RPA between wt and indicated mutant. Significance: ${ }^{*} p<0,05 ; * * p<0,01 ; * * *<0,001 ;$ ns $=$ not significant.

Figure S1. Mre11 nuclease deficiency and deletion of Sae2 do not affect Scc2 recruitment to a DSB 
ChIP-qPCR of Scc2 binding at the DSB in $(\mathbf{a}, \mathbf{b})$ wt and a) a nuclease deficient mre11 D56A (upper) and mre11 H125A (lower) b) a sae2 $\Delta$ strain. The graphs show means and SD of $\mathrm{n}=3$. Student's t-test was used to compare normalized values of Scc2 between wt and indicated mutants at respective locations, 90 minutes after break induction. Significance: ${ }^{*} p<0,05 ; * * p$ $<0,01 ; * * * p<0,001 ; \mathrm{ns}=$ not significant.

\section{Figure S2. Additional information on the relationship of Scc2 and DNA end resection}

a) Measurement of SsDNA at the DSB in the presence (red) and absence (blue) of Scc2 at indicated distances from the break. Samples were collected after addition of galactose for 0 , 90, 180 and 360 minutes. The graphs show means and SD of $n=3$. No significant difference was observed at any distance at any given time point using student's t-test. b) ChIP-qPCR of proximal Scc2 binding at a DSB in wt and a sgs $1 \Delta /$ exo1 $\Delta$ background. The graph shows means and SD of $n=2$. Student's t-test was used to compare normalized values of Scc2 between wt and $\operatorname{sgs} 1 \Delta /$ exo $1 \Delta$ at respective locations, 180 minutes after break induction. Significance: ${ }^{*} p$ $<0,05 ; *$ p $<0,01 ; * * p<0,001 ;$ ns = not significant.

Figure S3. Additional information on the chromatin remodelers in our experimental setup

a) Representative FACS analysis showing cell cycle distribution of indicated strains at different experimental time points. b) Protein levels of Scc2 in cycling cells in indicated strains. c) Southern blot showing successful break induction of chromosome VI of indicated strains from 3 independet repeats. The probe for chromosome VI was generated using primers $-1 \mathrm{~kb}$ and 0,3kb. A probe for chromosome $\mathrm{V}$ was used as a loading control (see Table S2). d) PFGE gel showing absence of a cut chromosome VI within 3 hours of break induction $(n=2)$. 
A

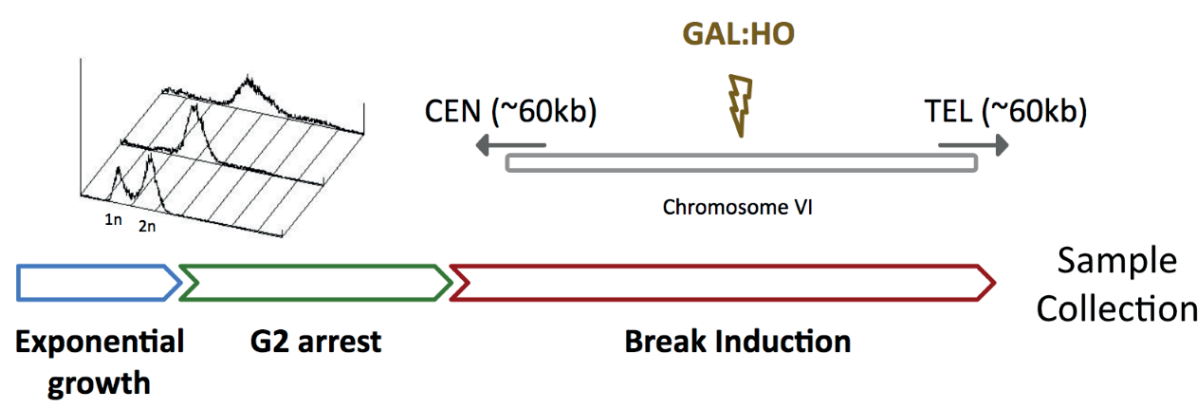

B

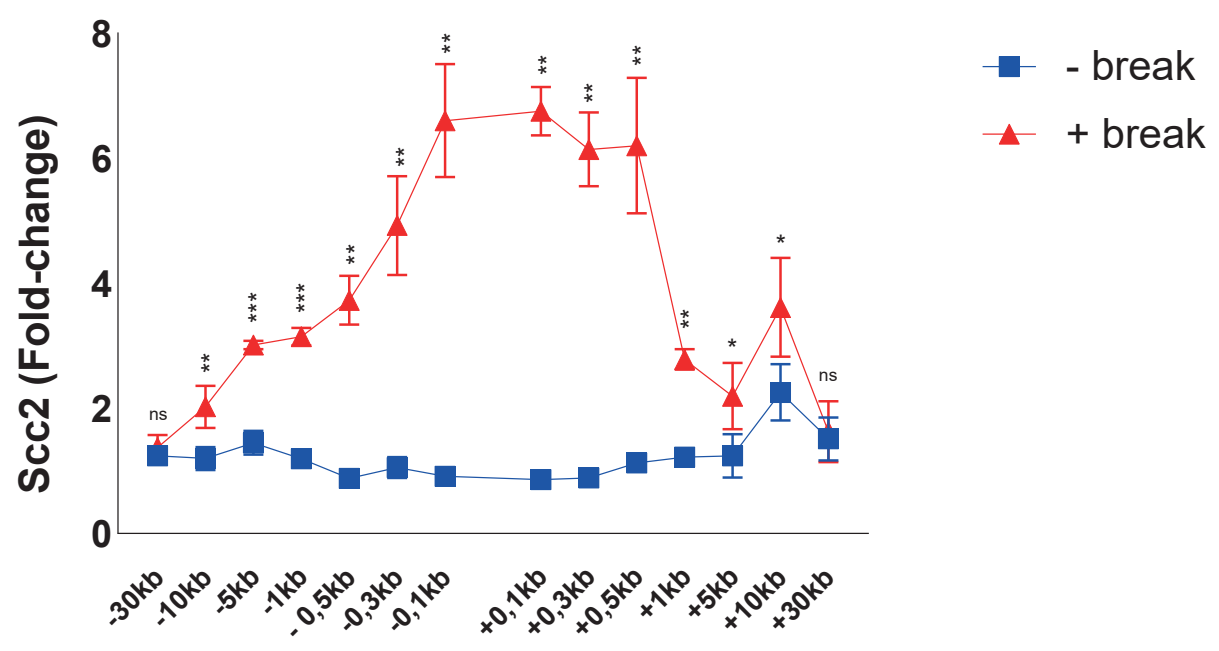

Distance from cut site 
A

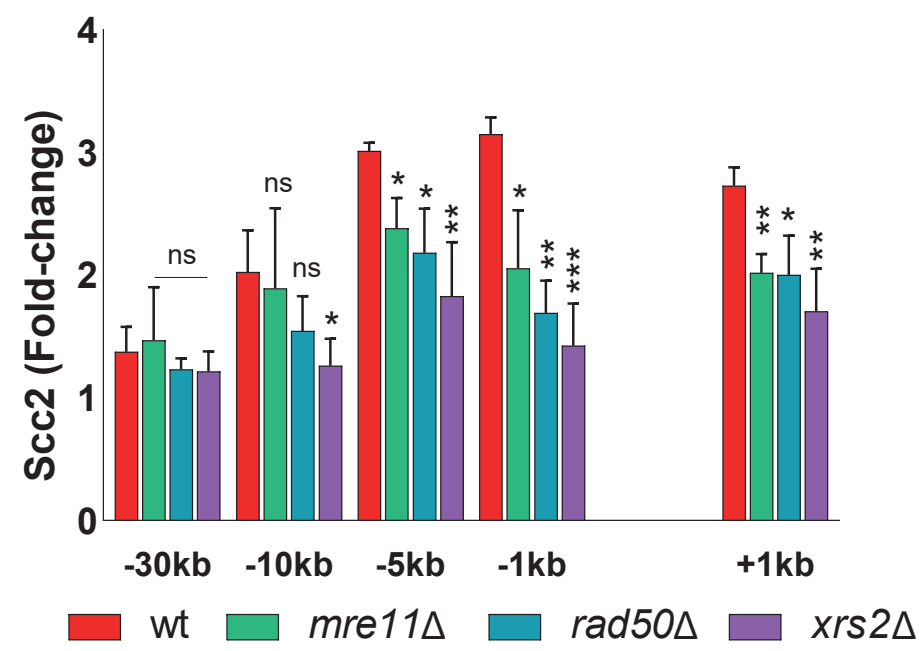

C

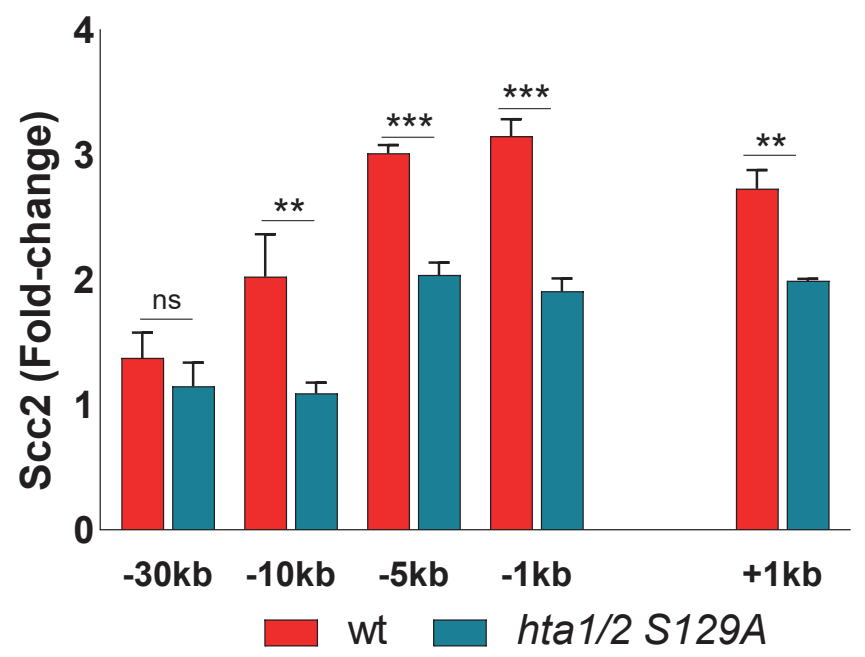

B

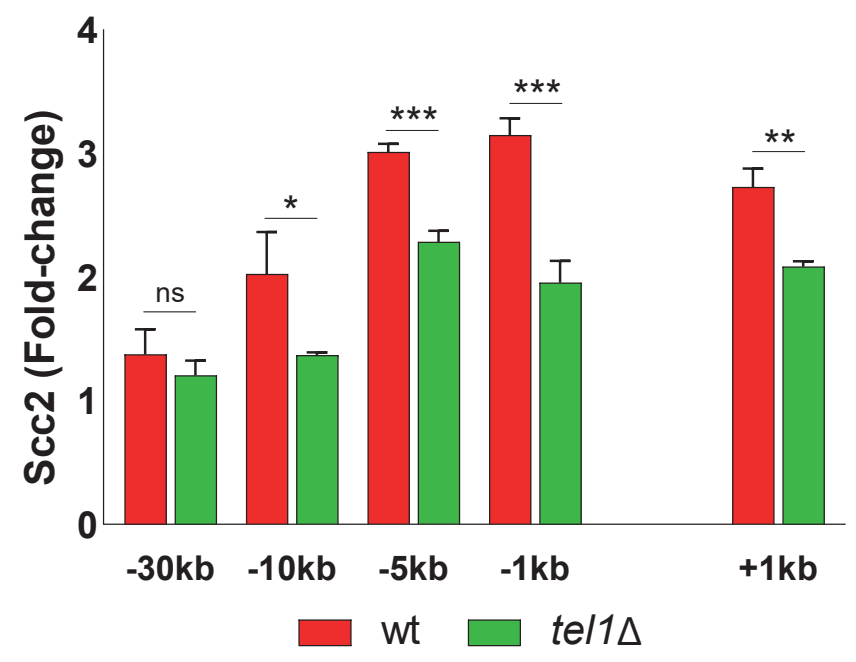

D

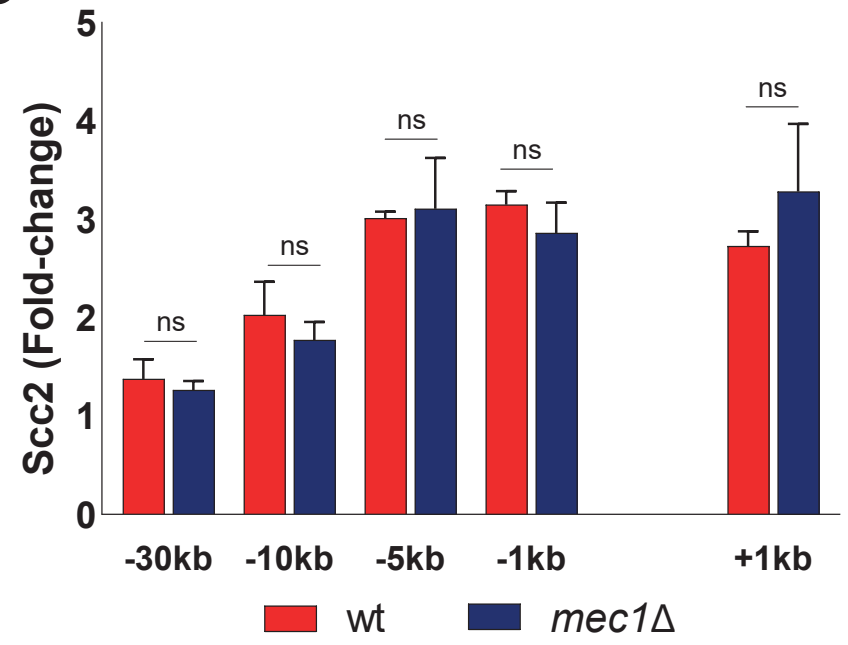


A

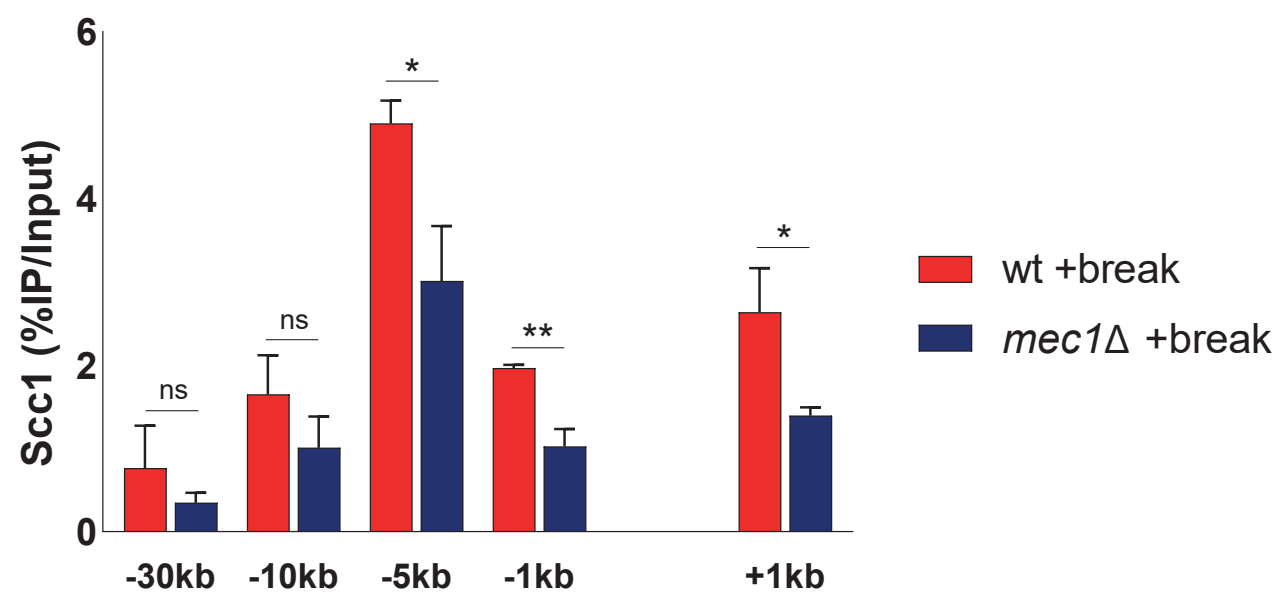

B
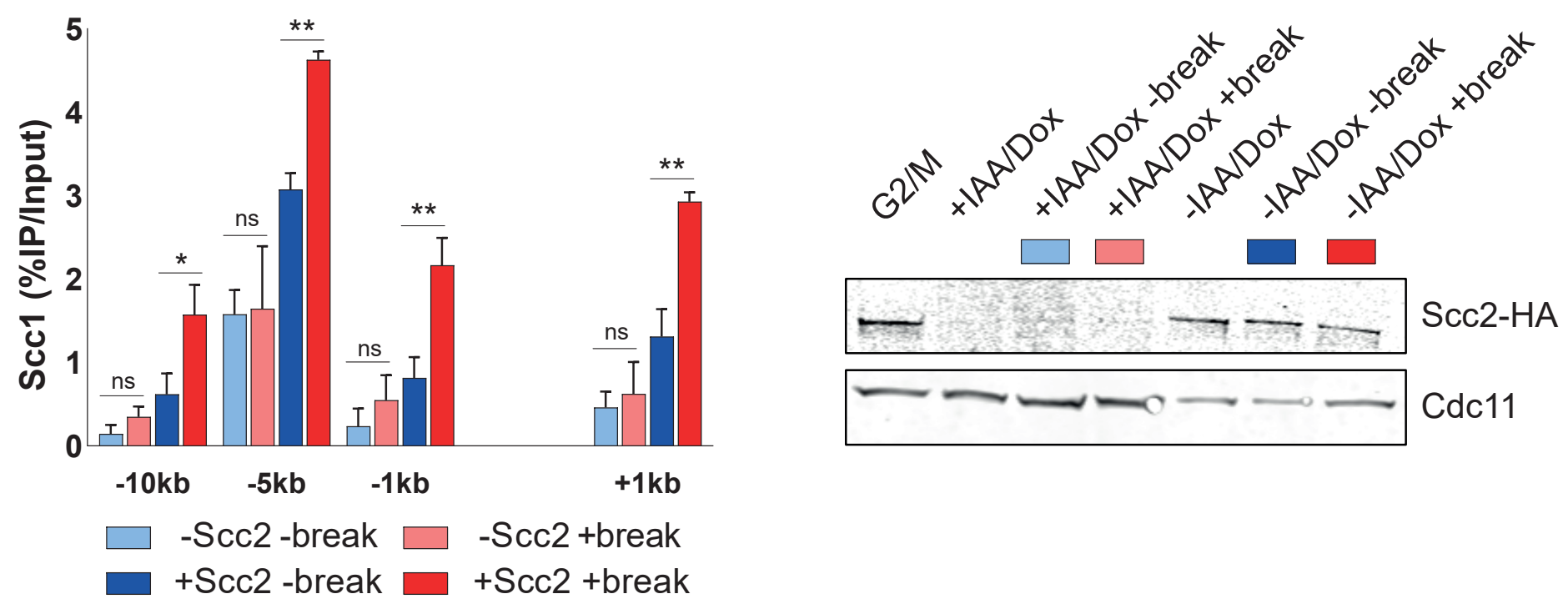
A

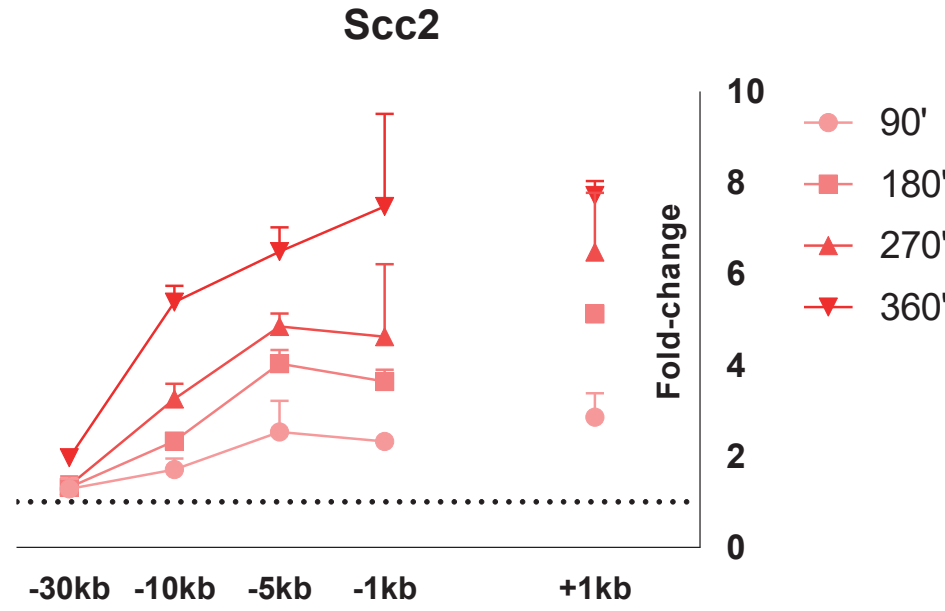

B

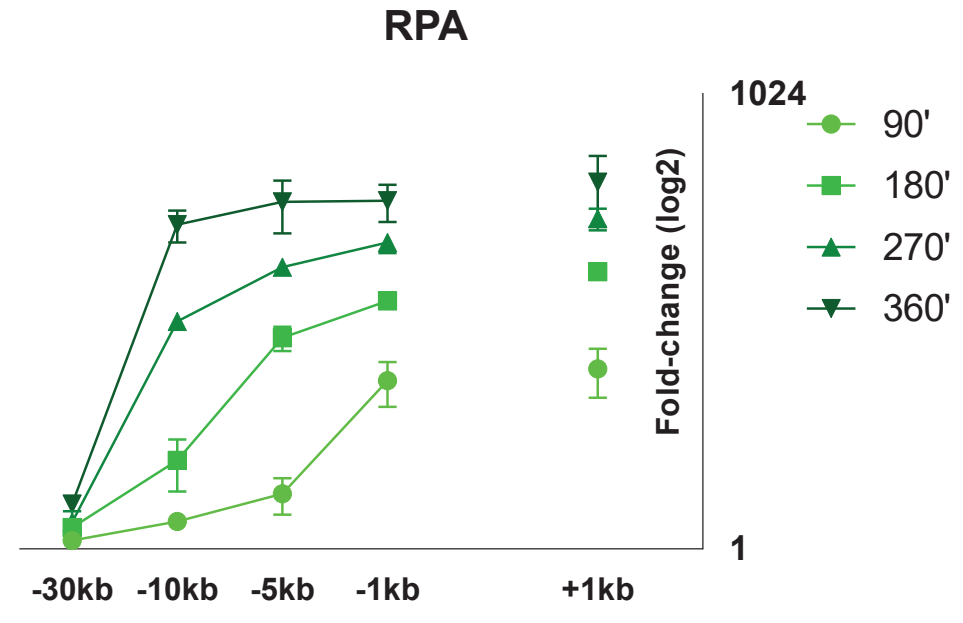

D

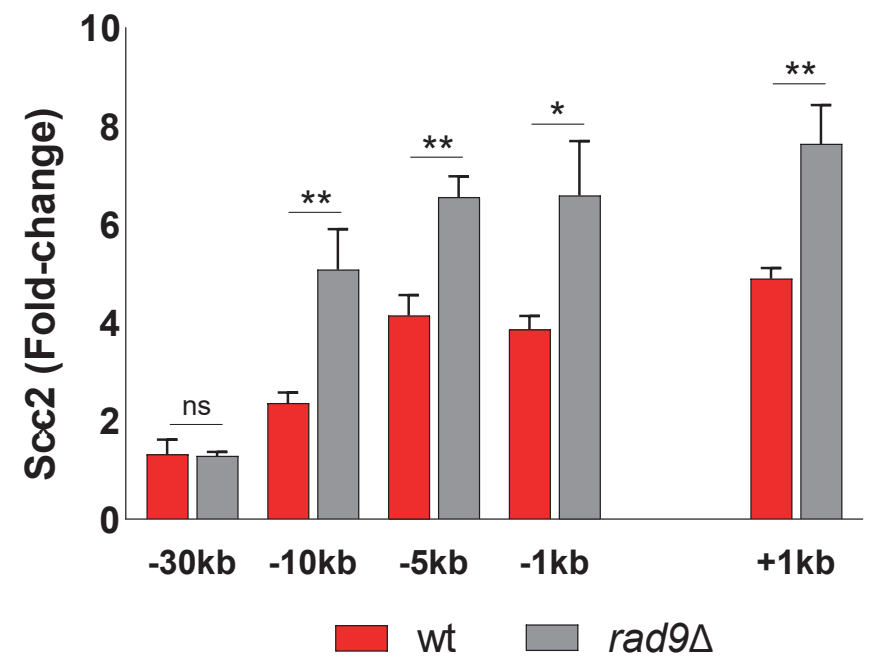

\section{E}
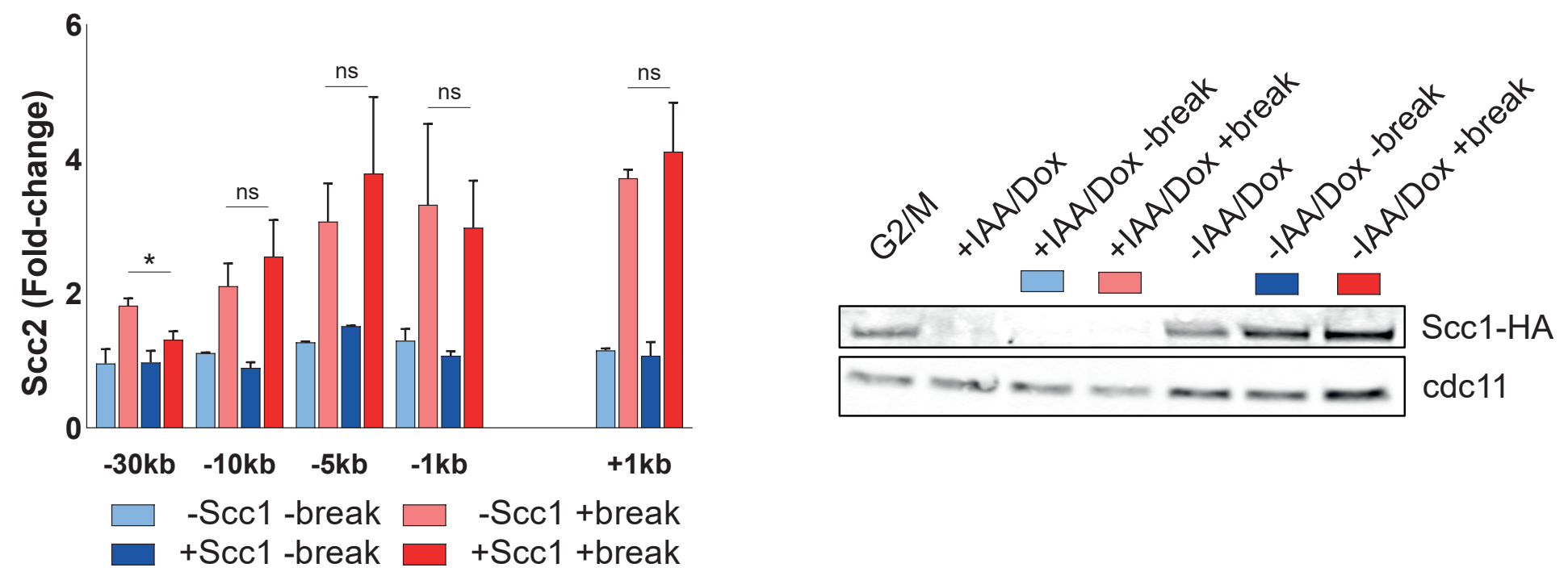
A

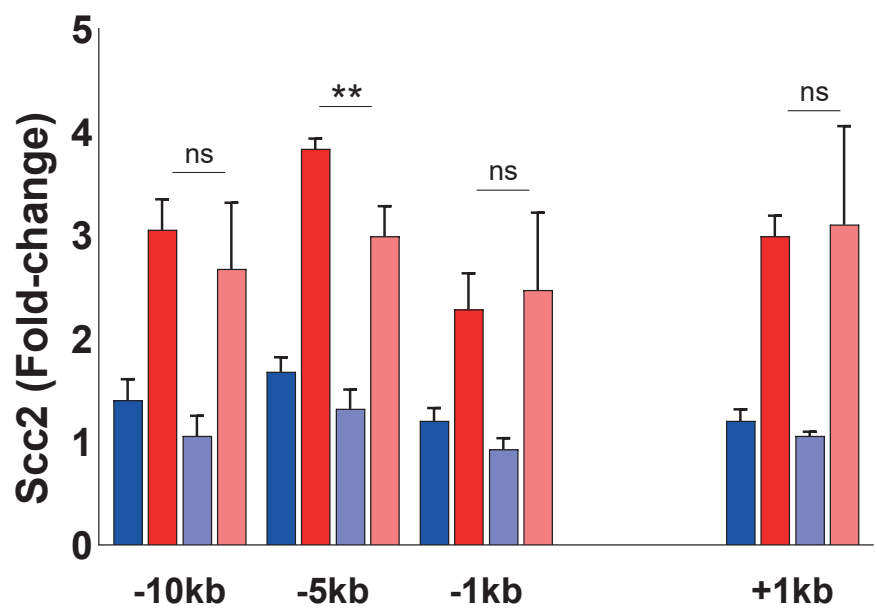

sth1-3 $\left(25^{\circ} \mathrm{C}\right)$-break

sth1-3 $\left(25^{\circ} \mathrm{C}\right)+$ break

$\square \operatorname{sth} 1-3\left(37^{\circ} \mathrm{C}\right)$-break

$\square \operatorname{sth} 1-3\left(37^{\circ} \mathrm{C}\right)+$ break

B
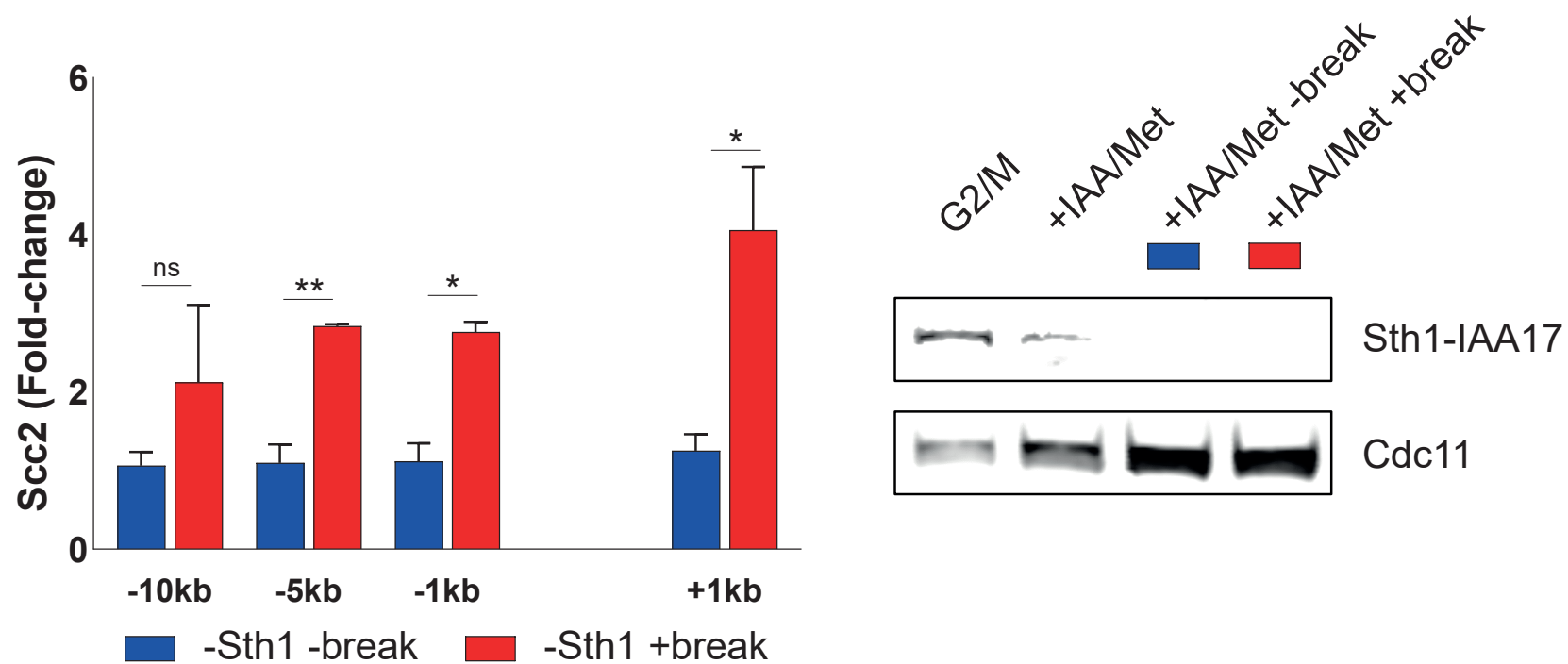

C
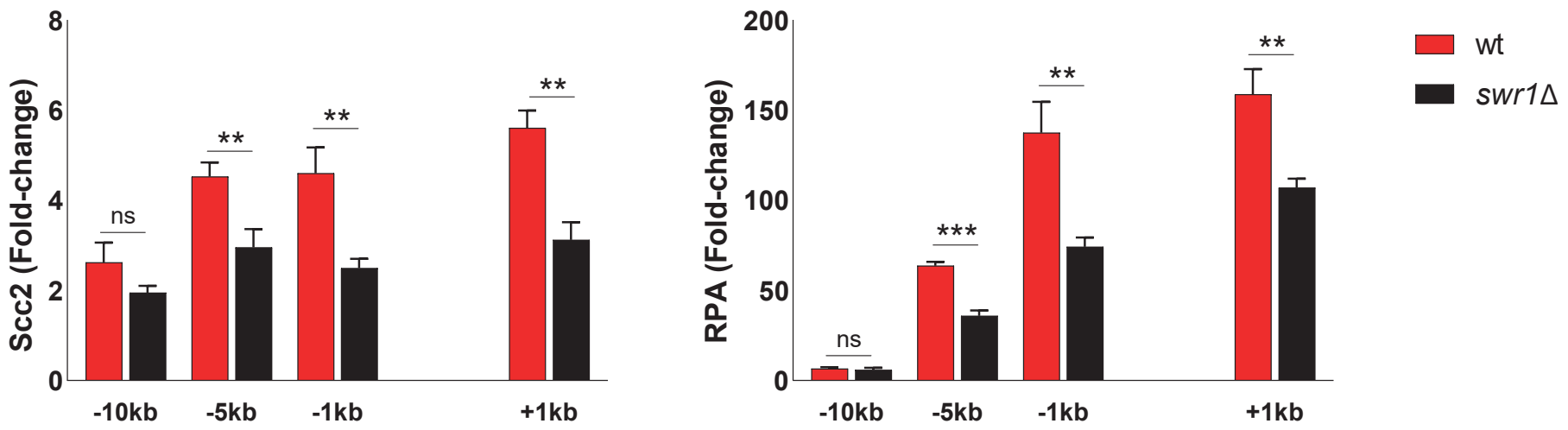

D
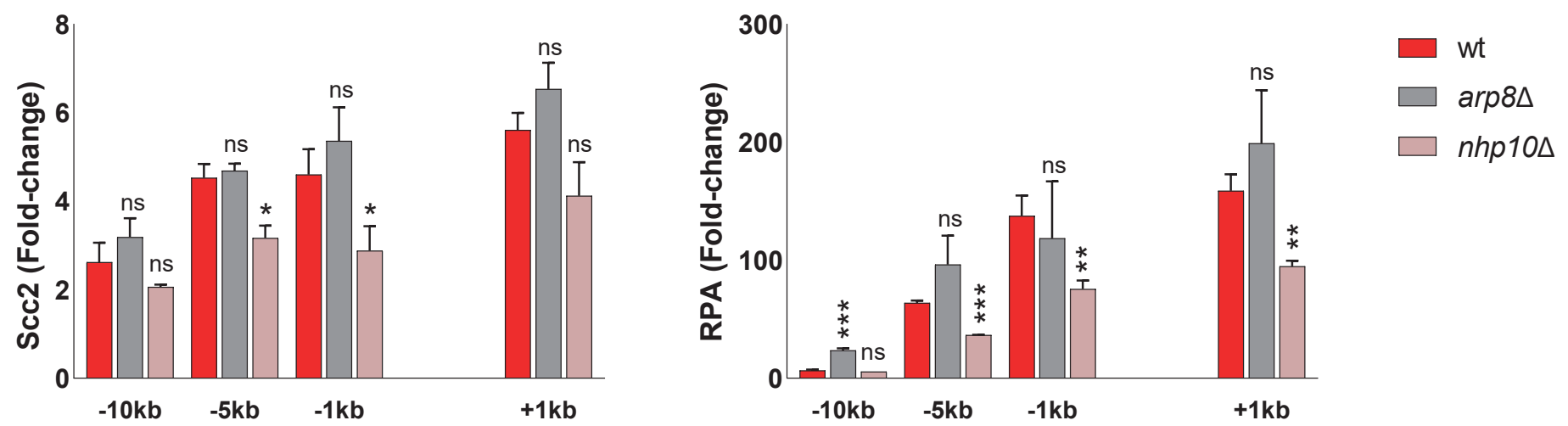


\section{Supplemental Figure 1}

A

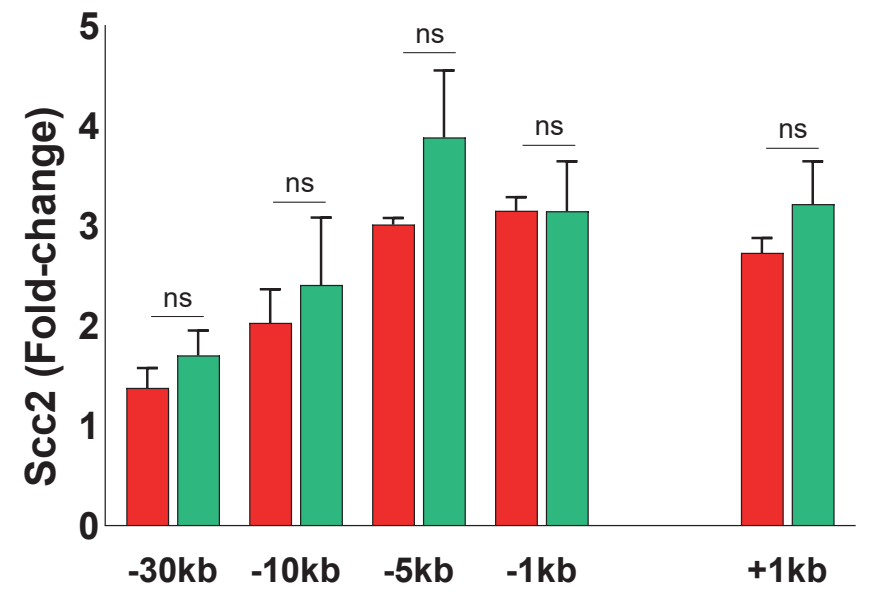

wt

mre11 D56A

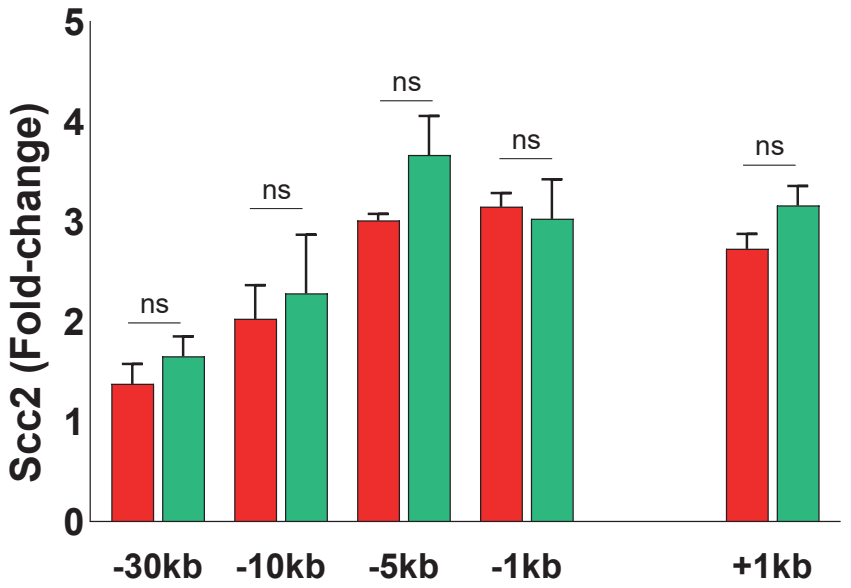

B

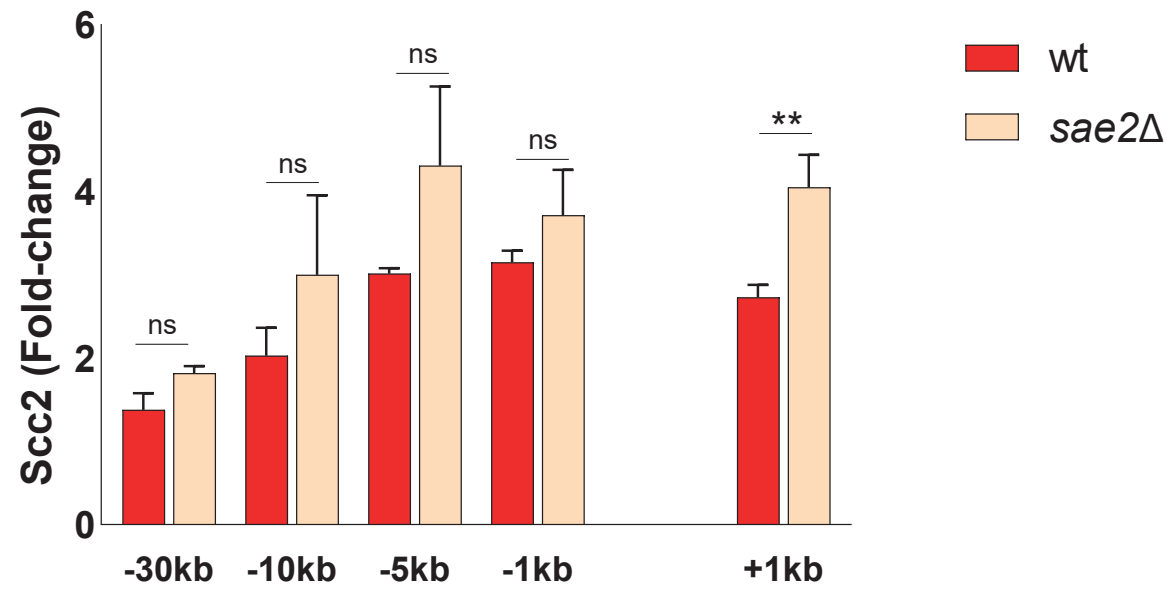


A
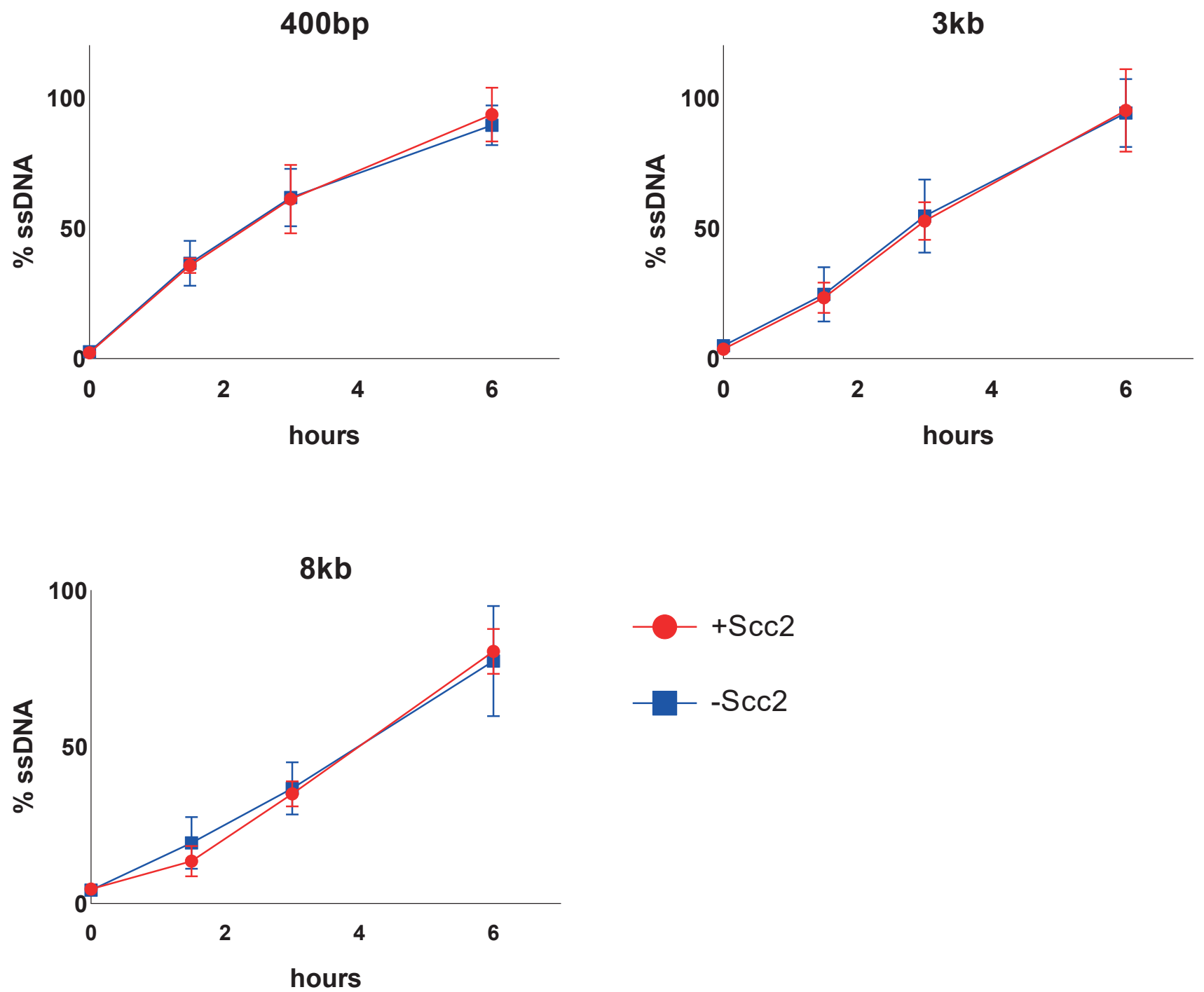

B

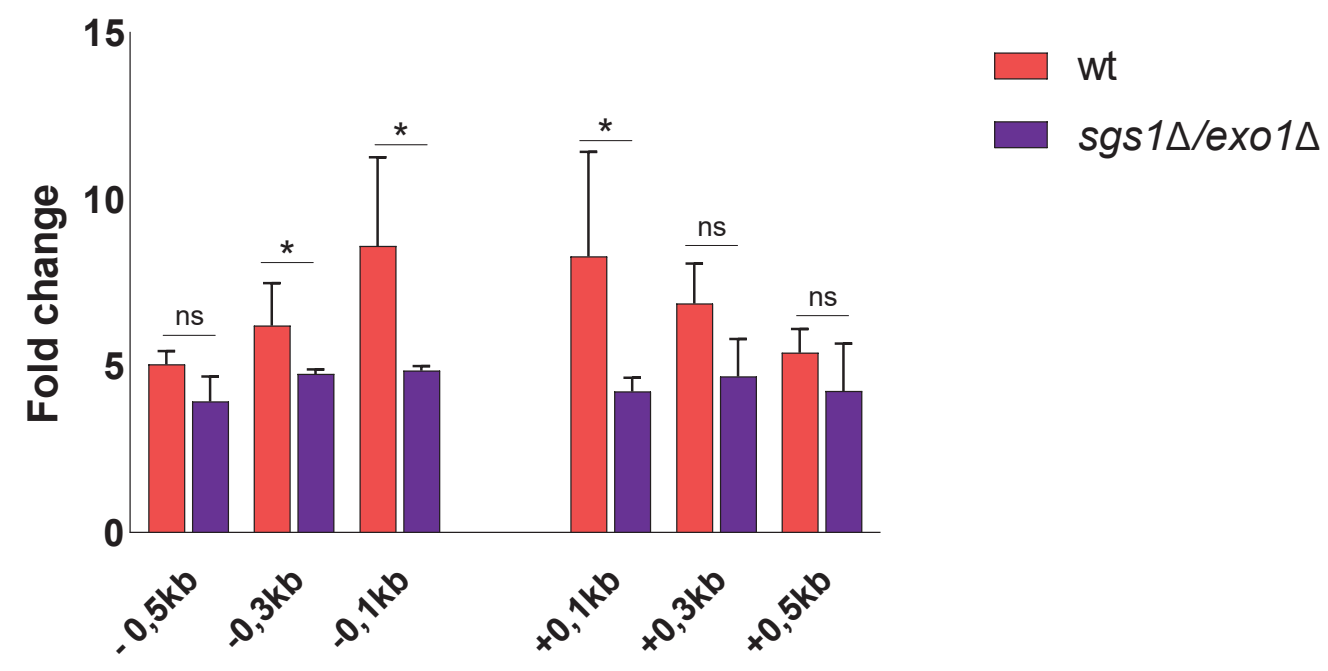


A

nhp104

B
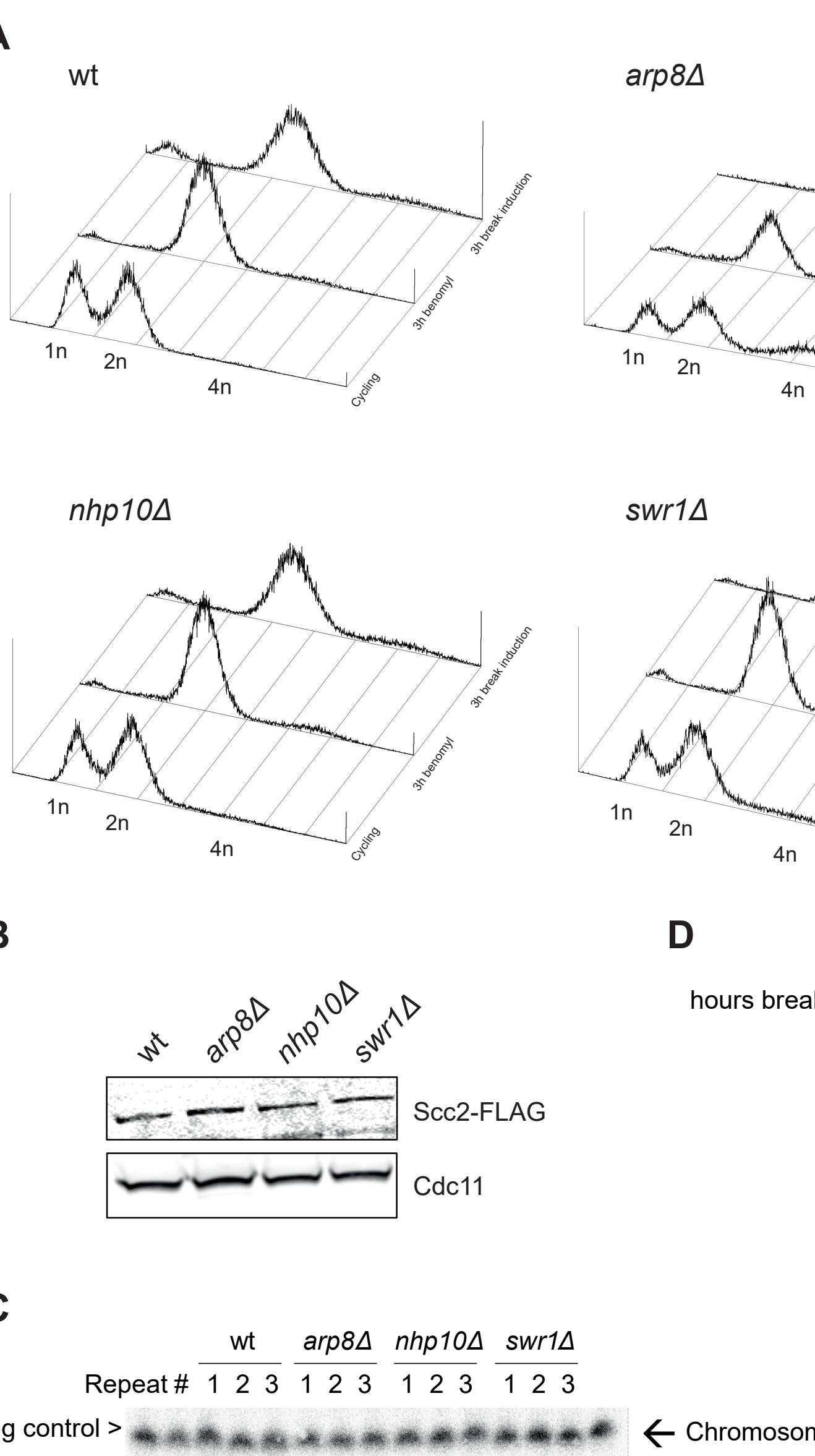

\section{$\operatorname{arp} 8 \Delta$}

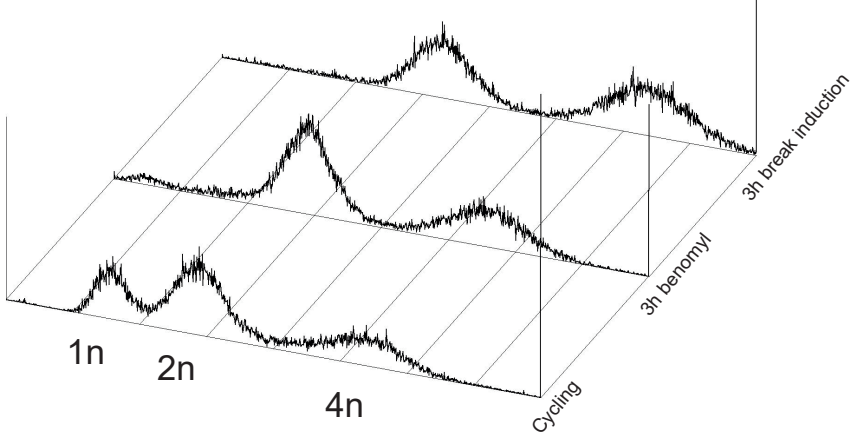

swr1

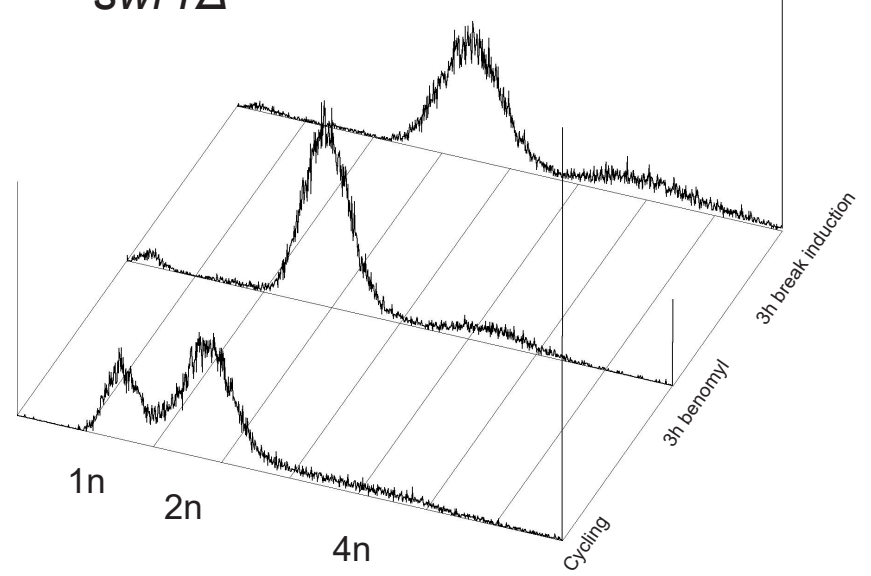

D

$h t z 1 \Delta$

C

Repeat \# $\frac{w t}{123} \frac{\operatorname{arp} 8 \Delta}{123} \frac{n h p 10 \Delta}{123} \frac{s w r 1 \Delta}{123}$

Loading control >

$\leftarrow$ Chromosome $V \rightarrow$

Uncut $>$ Cut $>$ 